Research Article

\title{
Evaluation of Soil Quality in Arid Western Fringes of the Nile Delta for Sustainable Agriculture
}

\author{
Ahmed M. Saleh ${ }^{D},{ }^{1}$ Mohamed M. Elsharkawy, ${ }^{2}$ Mohamed A. E. AbdelRahman $\mathbb{D}^{3}$ \\ and Sayed M. Arafat ${ }^{1}$ \\ ${ }^{1}$ Division of Agricultural Applications, Soils, and Marine Sciences, National Authority for Remote Sensing and Space Sciences, \\ Cairo, Egypt \\ ${ }^{2}$ Soils Department, Faculty of Agriculture, Beni Suef University, Beni Suef, Egypt \\ ${ }^{3}$ Division of Environmental Studies and Land Use, National Authority for Remote Sensing and Space Sciences, Cairo, Egypt
}

Correspondence should be addressed to Ahmed M. Saleh; ahmedms@outlook.com

Received 21 June 2021; Accepted 9 September 2021; Published 20 September 2021

Academic Editor: Fedor Lisetskii

Copyright (c) 2021 Ahmed M. Saleh et al. This is an open access article distributed under the Creative Commons Attribution License, which permits unrestricted use, distribution, and reproduction in any medium, provided the original work is properly cited.

\begin{abstract}
Egypt is currently witnessing an extensive desert greening plan with a target of adding one and a half million feddans to the agricultural area. The present study evaluates the soil quality in the western desert fringes of the Nile Delta using three indicator datasets, which involve the total dataset (TDS), the minimum dataset (MDS), and the expert dataset (EDS). Three quality index models are included: the Additive Soil Quality Index (SQI-A), the Weighted Additive Soil Quality Index (SQI-W), and the Nemoro Soil Quality Index (SQI-N). Linear and nonlinear scoring functions are evaluated for scoring soil and terrain indicators. Thirteen soil quality indicators and three terrain indicators were measured in 397 sampling sites for soil quality evaluation. Factor analyses determined five soil and terrain indicators for the minimum dataset and their associated weights. The linear scoring functions reflected the soil system functions more than nonlinear scoring functions. Soil quality estimation by the minimum dataset (MDS) and Weighted Additive Soil Quality Index (SQI-W) is more sensitive than that by SQI-A and SQI-N quality models to explain soil quality indicators. The moderate soil quality grade is the largest quality grade in the studied area. The minimum dataset of soil quality indicators could assist in reducing time and cost of evaluating soil quality and monitoring the temporal changes in soil quality of the region due to the increased agricultural development.
\end{abstract}

\section{Introduction}

Soil is considered one of the most important natural resources for countries where the foundations of human life are mainly based on their suitability for agriculture as well as other anthropogenic activities [1]. In the Eastern Mediterranean, the Egyptian civilization has sustained in the fertile Nile Valley and the Nile Delta, in which the elements of sustainability are available [2]. During the past century, there has been a serious deterioration in the productive capacity of more than $10 \%$ of the world's lands, which increased the interest in assessing soil health at the regional level [3]. Assessment of soil quality is necessary to assist farmers in evaluating the effects of their management decisions on soil productivity $[4,5]$. The study in [6] emphasized that soil qualitative evaluation, despite its simplicity and speed, requires very high experience. Accurate assessment of soil quality is complex due to the lack of consistency in soil characteristics [7-10] and the different soil management practices such as adding organic and mineral fertilizers, herbicides, and pesticides, which make the soil assessment more difficult [9]. Soil quality indicators are evaluated using different descriptive and quantitative approaches [6, 11-13]. The concept of soil quality is more comprehensive than the reductive approach of measuring a single indicator [14]. Basically, soil quality indices have three component targets as the environmental quality, agronomic sustainability, and socioeconomic feasibility [15]. Therefore, the estimation of 
soil quality indices is a complicated process and quite a hard mission [16]. Recently, several techniques have been successfully utilized for evaluating soil quality such as spectroscopy fingerprint [17], the Soil Management Assessment Framework (SMAF) [18], and spatial variability of physicochemical soil properties [19]. Most researchers estimated soil quality using only one technique with some exclusion [17-21]. Principal component analysis (PCA) and linear regression coefficients are also widely used for minimizing the number of soil variables included in estimating soil quality [21]. Recent studies attempted to develop appropriate algorithms and scoring functions for determining soil quality [22] by comparing multiple soil quality scoring techniques $[15,23,24]$.

To overcome the financial constraints, the amount of soil quality indicators needs to be reduced to a minimum dataset (MDS) [25, 26]. The concept of minimum datasets was proposed in [27], which is the lowest set of soil quality indicators required to measure or evaluate soil quality to demonstrate the soil's capacity for sustainable agricultural production. Recent soil quality studies preferred the minimum dataset (MDS) approach [28-30], where the MDS was favorable for detecting yield variations than the total dataset approach [31]. Additionally, the MDS approach is an effective tool for identifying the status of soil nutrients at the regional level [32]. The limitation factors of soil quality vary based on the soil topography, land use, climatic zone, the regional soil ecosystem, and the soil geological units $[33,34]$.

By establishing the MDS, it is easy to select the most effective indicators to determine soil quality determined based on its ability to estimate soil productivity and soil stability, and this indicator has been widely used [35-37]. Based on MDS indicators, the abundance of soil data can be minimized [10, 35]. Furthermore, the weight of chosen factors can be estimated while establishing the minimum datasets, thus minimizing the internal influence [37]. The MDS can be determined by linear or multiple regression factor analysis [38], multivariate statistical techniques $[9,37]$, discriminant analysis, and score function [34]. Since factor analysis can minimize abundant input data in the original soil datasets, it is widely utilized in the limitation of the MDS $[28,39]$. Factor analysis statistical techniques can identify the most important indicators discriminating soil quality in combined tillage, fertilization, and crop rotation treatments [28]. In Egypt, recent researchers evaluated soil quality in the Nile Delta and El-Fayoum depression [40-42].

As the calculation of soil quality is hard [4], an urgent need exists for improving the simple and reliable quantitative evaluation of soil quality through comparison of various available assessment strategies and methods. Thus, this study attempts to examine the soil quality in the arid region along the desert western fringes of the Nile Delta by (i) assessing the soil quality using three types of indicator datasets (TDS, MDS, and EDS), three types of linear scoring functions, two types of nonlinear scoring functions, and three soil quality index models (additive, weighted additive, and Nemoro quality indices); (ii) suggesting the most suitable indicator method and soil quality index model for the studied region using sensitivity analysis and linear relationships. The findings of the study have a significant value for assessing the soil quality in the rapidly developing area for sustainable management.

\section{Materials and Methods}

2.1. Field Description of the Study Area. The evaluated area is located in Wadi El Natrun district, El Beheira Governorate, at the western fringes of the Nile Delta between $29^{\circ} 54^{\prime} 00^{\prime \prime} \mathrm{E}-30^{\circ} 20^{\prime} 00^{\prime \prime} \mathrm{E}$ and latitudes of $30^{\circ} 22^{\prime} 00^{\prime \prime} \mathrm{N}-30^{\circ}$ $00^{\prime} 00^{\prime \prime} \mathrm{N}$ (Figure 1). The evaluated area covers an area of $1600 \mathrm{~km}^{2}$ (380000 feddan), with a landscape consisting of Wadi terraces and Wadi depressions with longitudinal sand dunes at the southern edge of the area [43]. The annual evaporation rate is about $114.3 \mathrm{~mm} / \mathrm{y}$, the average air temperature is $21^{\circ} \mathrm{C}$, and the area has a rarely annual precipitation rate with an average of $41.4 \mathrm{~mm} / \mathrm{y}$ [44] with an erratic distribution. Based on the work in [45], the soil temperature regime is "Thermic" and the moisture regime is "Torric." Two soil orders are dominant in the area, Entisols and Aridisols. The evaluated area has been reclaimed during the last two decades and is cultivated with diverse kinds of fruits and vegetables [46]. This kind of cultivation is usually associated with an increase of underground water irrigation, and the ongoing climate change put a threat on the soil quality and sustainable agriculture that reduces the economic value of the lands $[47,48]$. Additionally, the excessive extraction of groundwater for irrigation resulted in land subsidence, which could also affect the integrity of the soil profiles in the area [49].

\subsection{Data Collection}

2.2.1. Indicator Sampling Design. The required samples size needed for soil quality assessment was determined by using the binomial probability algorithm [50]. 397 sampling sites were chosen. A Proportionate Stratified Random (PSR) sampling technique was used as the sampling type for soil and terrain sampling based on land cover and land use distribution in the evaluated area. The sampling locations were georeferenced (Figure 1) using the Global Positioning System (GPS).

2.2.2. Sampling and Analyses. The soil sampling was carried out according to the sampling design. However, some sampling sites were displaced by other sampling sites near the designed sampling locations due to accessibility difficulties, and some certain areas were currently restricted for access, also the presence of elongated sand dunes at the south of the study area. These accessibility limitations resulted in ununiform spatial sampling distribution.

Disturbed and undisturbed samples were collected to the depth of the root zone $(30 \mathrm{~cm})$ and described according to the work in [51]. Soil samples were crumbled gently by hand without root material and were air dried, grounded, and sieved through a $2 \mathrm{~mm}$ sieve. Soil chemical analysis, including $\mathrm{pH}$ in 1 : 2.5 soil-water suspension, electrical conductivity (EC) in soil 


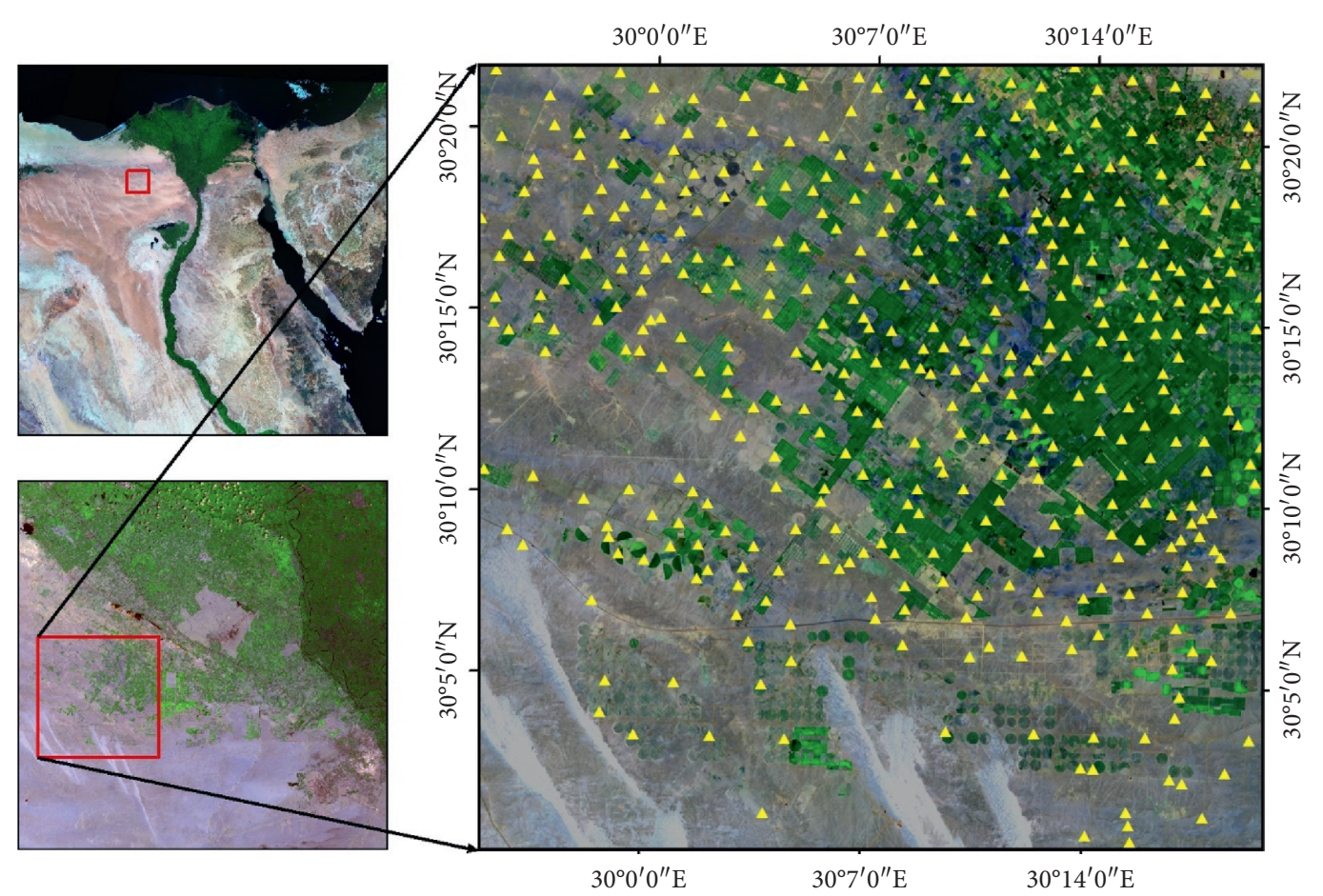

Figure 1: Location of the study area and soil sampling sites.

paste extract, cation exchange capacity (CEC), exchangeable sodium percentage (ESP), organic matter (OM), and calcium carbonate were determined according to standard methods of [52]. Soil physical analyses, including particle size distribution using the pipette method, bulk density (BD) using a core method, available water holding capacity (AWHC), and field capacity (FC), were performed according to the work in [53]. Soil packing density (PD) was estimated as a composite index of soil bulk density and soil clay content according to the work in [54].

Terrain analyses were performed on a shuttle radar topography mission (SRTM) 1-arc-second v.30 image [55] to obtain some surface parametric information (elevation, slope, relief intensity, and topographic witness index) [56]. The DEM image was firstly sink filled using depression filling algorithm [57]. The slope (Slp) and topographic witness index (TWI) were extracted $[58,59]$. The extraction of relief intensity (Rlf) was based on the algorithm described in [60].

The Normalized Difference Vegetation Index (NDVI) and elevation data were used as exterior environmental variables in the process of representative indicator selection and redundancy reduction. NDVI data were retrieved from the Landsat Data Continuity Mission (LDCM) sensor multiband dataset using the NDVI equation ([61, 62]).

All of the datasets were projected into the WGS84-based Universal Transverse Mercator (UTM) orthographic projection coordinate system (EPSG 32636) and resampled to a $30 \mathrm{~m}$ spatial resolution.

2.3. Indicator Selection and Scaling. Three datasets of quality indicators were chosen, the total dataset (TDS), minimum dataset (MDS), and expert opinion dataset (EDS). The total dataset (TDS) includes all soil and terrain indicators for soil quality index development. The soil and terrain indicators for the minimum dataset were determined according to multivariate factor analysis. Factor analysis reduces the dimension of data while minimizing the loss of information [63]. For the expert opinion dataset (EDS), the authors of the current study selected the soil and terrain indicators for the EDS considering the arid climatic characteristics coupled with low annual perception rate and the associated pedogenic soil processes which plays a major role in forming of soil properties, the gathered knowledge of the evaluated area about the cost of sampling, environmental functions, management practices, vulnerability to productivity, and previous literature recommendations $[5,25,64-66]$. The EDS includes soil electrical conductivity (EC), soil organic matter content (OM), calcium carbonate content $\left(\mathrm{CaCO}_{3}\right)$, available water holding capacity (AWHC), soil packing density (PD), and topographic witness index (TWI).

The soil quality indicators were rescaled to a Z-score with standard normal distribution where they are centered around a mean of zero (0) and standard deviation of 1 as the indicators are of different measurement units and scales. The $Z$-score standardization ensures that the indicators have an equal order of magnitude [67].

2.4. Minimum Dataset (MDS) Formulation. A minimum dataset (MDS) of soil and terrain indicators was selected from the indicator dataset through multivariate statistical analysis. The minimum dataset selection process includes two steps: representative indicators selection and indicator redundancy reduction. Representative indicators were selected by applying multivariate factor analysis, and the 
redundant indicators were reduced by vector norm (Norm) analysis.

Factor analyses were performed with the covariance matrix of the raw soil and terrain indicators values using principal axis as a factoring method, diagonals equal to 1 as prior communality, and unrotated factor loadings for model parameters. The total dataset includes sand, silt, clay, $\mathrm{pH}, \mathrm{EC}, \mathrm{OM}, \mathrm{ESP}$, $\mathrm{CEC}, \mathrm{CaCO}_{3}, \mathrm{FC}, \mathrm{AWHC}, \mathrm{BD}, \mathrm{PD}$, Slp, Rlf, and TWI.

The raw soil and terrain indicator covariance revealed that the first nine principal components (PCs) account for $0.99 \%$ of the total variance of soil and terrain indicators data. The first principal component explains only about $58 \%$ of the total variance of soil and terrain indicators, while the second principal components explain about $19 \%$ of the total variance. For the other principal components, the contributing indicators were of lowering contribution with a minimum of $r=0.30$.

Due to the difference in soil and terrain indicator units of measurements and scales and other than the first and second principal components, the remaining principal components explain only about $23 \%$ of the total variability of soil and terrain indicators. This led to the inadequacy of the covariance analyses, and therefore, factor analyses were recomputed based on the correlation matrix of the standardized soil and terrain indicator values where each indicator has a mean centered around zero (0) and standard deviation of unit variance with total variance equal to the number of indicators. Varimax rotation was performed to maximize the relationship between factors and indicators as each indicator has either a small or large loading on each factor [68]. Only factors with eigenvalues more than one were retained as they explain variation in the indicators and not the other factors [69]. For each factor based on the previous criteria, the indicators which contribute with highly weighted factor loadings (within $10 \%$ of highest factor loading or absolute value $>0.85$ ) were identified and retained for the minimum dataset (MDS).

An indicator value for each representative indicator was calculated, if there were more than one indicator for a single factor to reduce redundancy and exclude pseudo-indicator grouping. At first, for each factor, the soil and terrain indicators that have a factor loading more than or equal to 0.5 were grouped into one group. Any indicator that has all factor loads in the different factor that is more or equal to 0.5 was grouped with the smallest correlations with other indicators. If there is a correlation coefficient less than 0.3 between any indicator and the other indicators, the indicator is placed in another separate group.

The factor loadings for selecting soil and terrain indicators for the minimum dataset are not enough as they may ignore some important indicators as the eigenvectors do not express the magnitude (norm) of the resulting factor vectors or for the original indicators [70]. Therefore, for each representative soil and terrain indicator, a vector norm value which represents the magnitude of the vector representing the indicator was calculated $[21,70,71]$ according to the following equation:

$$
N_{i}=\sqrt{\sum_{j=1}^{k} \mu_{i j}^{2} \lambda_{i}}
$$

where $N_{i}$ is the combined factor load of indicator $i$ in all factors with eigenvalues $\geq 1, u_{i j}$ is the factor load of indicator $i$ in factor $j$, and $\lambda_{j}$ is the eigenvalue of factor $j$.

Secondly, a regression coefficient of determination $\left(R^{2}\right)$ was calculated for each pair of the exterior environmental variables with each of soil and terrain indicators as soil quality influenced by the interior properties and the exterior environment variables [72]. The indicator value was calculated by employing a standard transformation function sum to the vector norm of each indicator with the coefficient of determination $R^{2}$ for that indicator with the exterior environment variables.

2.5. Indicator Weighting. For soil quality index (SQI) formulation, soil and terrain indicators of the three datasets (TDS, MDS, and EDS) were weighted. Each soil and terrain indicator of the total dataset (TDS) and expert opinion dataset (EDS) weighted by calculating the ratio of its respective indicator's communality resulted from factor analysis and the total indicator communality summation for the dataset $[36,73]$. For the minimum dataset (MDS), each indicator was weighted by determining the variation of each respective factor, normalized to unity to the common factor variance summation for the minimum dataset [15] as follows:

$$
\mathrm{Iw}_{\mathrm{mds}}=\frac{v_{i j_{\mathrm{mds}}}}{\sum_{i=1}^{k} v_{j_{\mathrm{mds}}}}
$$

where $\mathrm{Iw}_{\mathrm{mds}}$ is the weight for the minimum dataset indicator, $v_{i j_{\mathrm{mds}}}$ is the variance of the indicator $I$ for factor $j$, and $v_{j_{\text {mds }}}$ is the common factor variance of the minimum dataset indicator.

2.6. Indicator Scoring Functions. The soil and terrain indicators are of different measurement units and scales, though there is a need for a normalized transformation of soil and terrain indicator measured values to a unitless score ranging from a zero to one scale [15]. The scoring of indicators provides the capability of combining and averaging the scores into a single value nonlimiting to the pertinent soil functions and processes [74] and to capture information that might otherwise go undetected when examining only the observed values [75]. Linear and nonlinear scoring functions were widely used for quality indicator scoring $[15,76-78]$.

The indicator scoring function relies on critical threshold values which are soil property values determining the upper limit (threshold) where the indicator score is at the most preferable level (score $=1$ ), the lower limit (lower threshold) where the indicator score is at the inadmissible level, and baseline values (minimum target thresholds) where the scoring function equals 0.5 at the lower and upper target thresholds for soil property values [79-82]. The critical threshold values for normalizing indicators values (Table 1) were determined based on the measured values of soil and quality indicators, expert 
TABLE 1: Soil quality scoring functions (SSFs) and thresholds values for soil and terrain quality indicators.

\begin{tabular}{|c|c|c|c|c|c|c|c|c|c|}
\hline \multirow{2}{*}{ Indicator } & \multirow{2}{*}{ SSF } & \multicolumn{2}{|c|}{ Thresholds } & \multirow{2}{*}{$B$} & \multirow{2}{*}{$O$} & \multirow{2}{*}{$L_{1}$} & \multirow{2}{*}{$U_{1}$} & \multirow{2}{*}{$S$} & \multirow{2}{*}{ Sources } \\
\hline & & $L$ & $U$ & & & & & & \\
\hline Sand & $\mathrm{SSF}_{5}$ & 0 & 60 & - & 35 & 30 & 50 & 0.440 & [89] \\
\hline Silt & $\mathrm{SSF}_{3}$ & 0 & 25 & 10 & - & - & - & 0.249 & [89] \\
\hline Clay & $\mathrm{SSF}_{3}$ & 0 & 30 & 15 & - & - & - & 0.268 & {$[89]$} \\
\hline $\mathrm{pH}$ & $\mathrm{SSF}_{5}$ & 4.5 & 9.5 & - & 7.00 & 6.5 & 7.7 & 1.301 & {$[3,75,83,84,90,96,97]$} \\
\hline $\mathrm{EC}^{\mathrm{a}, \mathrm{b}}$ & $\mathrm{SSF}_{5}$ & 0.0 & 2 & - & 1 & 0.25 & 1.75 & 2.234 & {$[84,90,96,97]$} \\
\hline $\mathrm{OM}^{\mathrm{a}, \mathrm{b}}$ & $\mathrm{SSF}_{3}$ & 0.2 & 2 & 1 & - & - & - & 1.049 & {$[36,86,96-98]$} \\
\hline ESP & $\mathrm{SSF}_{9}$ & 2 & 15 & 5 & - & - & - & 2.50 & {$[15,39,66,99-101]$} \\
\hline $\mathrm{CEC}^{\mathrm{a}}$ & $\mathrm{SSF}_{3}$ & 0 & 21 & 10.5 & - & - & - & 0.245 & {$[36,82,89,96,102,103]$} \\
\hline $\mathrm{CaCO}_{3}{ }^{\mathrm{b}}$ & $\mathrm{SSF}_{9}$ & 1 & 8 & 3 & - & - & - & 2.50 & NE, EO \\
\hline FC & $\mathrm{SSF}_{3}$ & 15 & 25 & 20 & - & - & - & -2.50 & NE, EO \\
\hline $\mathrm{AWHC}$ & $\mathrm{SSF}_{3}$ & 2 & 10 & 4 & - & - & - & 0.198 & {$[80,85] ; \mathrm{NE}$} \\
\hline $\mathrm{BD}$ & $\mathrm{SSF}_{9}$ & 1.00 & 2.0 & 1.50 & - & - & - & $\begin{array}{c}-2.62 \\
-0.323\end{array}$ & {$[104,105]$} \\
\hline $\mathrm{PD}^{\mathrm{b}}$ & $\mathrm{SSF}_{9}$ & 1.00 & 1.50 & 1.2 & - & - & - & 2.50 & {$[81,97,106,107]$} \\
\hline $\operatorname{Slp}^{\mathrm{a}}$ & $\mathrm{SSF}_{9}$ & 2.00 & 4.00 & 3.00 & - & - & - & 2.50 & NE, EO \\
\hline Rlf & $\mathrm{SSF}_{9}$ & 3 & 10 & 5 & - & - & - & 2.50 & NE, EO \\
\hline $\mathrm{TWI}^{\mathrm{b}}$ & $\mathrm{SSF}_{9}$ & 5 & 15 & 10 & - & - & - & 2.50 & NE, EO \\
\hline
\end{tabular}

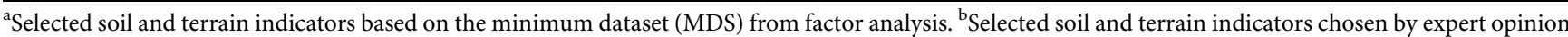
based on the natural ecosystem. NE: natural ecosystem, EO: expert opinion. For $\mathrm{SSF}_{3}$ : L, lower threshold, at which or below the score is 0; B, baseline, at which score is $0.5 ; \mathrm{U}$, upper threshold, at which or above score is 1.0. For $\mathrm{SSF}_{5}$ : $\mathrm{L}$, lower threshold, at which or below the score is 0 ; $\mathrm{L}_{1}$, lower baseline is 0.5 with bellshaped relationship; $\mathrm{O}$, optimum level, at which score is 1.0; $\mathrm{U}_{1}$, upper baseline is 0.5 with bell-shaped relationship; and $\mathrm{U}$, upper threshold, at which or above score is 0 . For $\mathrm{SSF}_{9}$ : $\mathrm{L}$, lower threshold, at which or below the score is $1 ; \mathrm{B}$, baseline, at which score is 0.5 ; and $\mathrm{U}$, upper threshold, at which or above score is 0 . $\mathrm{S}$, slope at baseline for nonlinear scoring functions.

knowledge for the natural ecosystem of the evaluated area, and guidance of the previous literature [80-90].

The soil and terrain indicator datasets (TDS, MDS, and EDS) were scored by transforming data values using linear and nonlinear scoring techniques as described below.

2.6.1. Linear Scoring Functions. Three linear scoring functions (LSFs) were identified and evaluated for scoring soil and terrain indicators: Leibig Linear Scoring Function (LLSF), Homothetic Linear Scoring Function (HLSF), and Glover Linear Scoring Function (GLSF).

The soil and terrain indicators were scored according to Liebig scoring function [77] into two orders in terms of soil function: ascending order which is more is better and descending order which is "less is better." In the ascending order "more is better order," the indicator value was divided by the maximum indicator values where it is equal to one score (equation (3)). In the descending order "less is better," the minimum indicator value was divided by the indicator value where the indicator minimum value is equal to one score (equation (4)).

$$
\begin{aligned}
& \operatorname{LLSF}\left(Y_{m}\right)=\frac{x}{x_{\text {max }}}, \\
& \operatorname{LLSF}\left(Y_{l}\right)=\frac{x_{\text {min }}}{x},
\end{aligned}
$$

where $X$ is the indicator value and $X_{\min }$ and $X_{\max }$ are the minimum and maximum value of each indicator, respectively.
The soil and terrain indicators were scored using a homothetic scoring function $[15,24,91]$. Three types of homothetic scoring functions were used for standardizing the quality indicators to a score value ranging between zero and one: $\mathrm{S}$ scoring function $\left(\mathrm{HLSF}_{3}\right)$, reverse scoring function $\left(\mathrm{HLFS}_{9}\right)$, and parabola scoring function $\left(\mathrm{HLSF}_{5}\right)$ [73, 76, 79-82]. For the ascending order "more is better," $\mathrm{HLSF}_{3}$ scoring function was applied (equation (5)), for "less is better," $\mathrm{HLSF}_{9}$ scoring function was applied (equation (7)), and for "optimum," where the indicator value scored as "more is better" until a critical threshold value where it is assigned "less is better," $\mathrm{HLSF}_{5}$ scoring function was applied (equation (6)).

The standard scoring functions (SSFs) are defined as follows:

$$
\begin{aligned}
& \mathrm{HLSF}_{3}: f(x)= \begin{cases}0.1, & x \leq L, \\
0.1+\frac{0.9(x-L)}{U-L}, & L \leq x \leq U, \\
1.0, & x \geq U,\end{cases} \\
& \mathrm{HLSF}_{5}: f(x)= \begin{cases}0.1, & x<L, x>U, \\
0.1+\frac{0.9(x-L)}{U-L}, & L \leq x<L_{1}, \\
1-\frac{0.9(x-L)}{U-L}, & U_{1}<x \leq U, \\
1.0, & L_{1}<x<U_{1},\end{cases}
\end{aligned}
$$




$$
\mathrm{HLSF}_{9}: f(x)= \begin{cases}1.0, & x \leq L, \\ 1-\frac{0.9(x-L)}{U-L}, & L \leq x \leq U, \\ 0.1, & x \geq U,\end{cases}
$$

where $f(x)$ is the scoring function and $x$ is the soil property value. For $\mathrm{SSF}_{3}$ : $L$ - lower threshold and $U$ - upper threshold. For $\mathrm{SSF}_{5}: L$ - lower threshold and $L_{1}$ - lower baseline is 0.5 with a bell-shaped relationship; $U_{1}$ - upper baseline is 0.5 with a bell-shaped relationship; and $U$ - upper threshold. For $\mathrm{SSF}_{9}$ : $L$ - lower threshold and $U$ upper threshold.

The soil and terrain indicators were scored using Glover linear scoring function $[82,87,88]$. The quality indicators were scored into two orders in terms of soil function: ascending order which is more is better and descending order which is "less is better." In the ascending order "more is better order," equation (8) was used for scoring, and for the descending order "less is better," equation (9) was used, while for the values outside the lower and upper thresholds, the indicator scored as zero. A combination of both "more is better" and "less is better" was used for the "optimum is better" soil function.

$$
\begin{aligned}
\operatorname{GLSF}\left(Y_{m}\right) & =\frac{x-s}{t-s} \\
\operatorname{GLSF}\left(Y_{l}\right) & =1-\frac{x-s}{t-s},
\end{aligned}
$$

where $Y_{m}$ is the linear score for "more is better," $Y_{l}$ is the linear score for "less is better," $x$ is the indicator value, and $s$ and $t$ are lower and upper threshold values.

2.6.2. Nonlinear Scoring Function (NLSF). Two nonlinear scoring functions (NLSFs) were identified and evaluated for scoring soil and terrain indicators: Sigmoid Nonlinear Scoring Function (SNLSF) and Glover Nonlinear Scoring Function (GNLSF).

The soil and terrain indicators were scored using sigmoid nonlinear scoring function [88, 92, 93]. The used sigmoid function for indicator scoring was the logistic nonlinear curve equation (equation (10)) where it is characterized as an S-shaped curve [94]. The scores of the sigmoid function are between zero and one.

$$
\operatorname{SNSLF}(Y)=\frac{a}{1+\left(x / x_{o}\right)^{b}},
$$

where $Y$ is the nonlinear score of the indicator value, $a$ is the maximum score, $x$ is the indicator value, $x_{o}$ is the mean value of the indicator, and $b$ is the slope of the curve.

The soil and terrain indicators were scored using Glover nonlinear scoring function [82, 87, 88] (equation (11)). Three types of GNLSF scoring were applied: the "more is better" scoring curve for positive slopes, "less is better" scoring curve for negative slopes, and a combination of "Optimum" curve defined by the combination of both "more is better" and "less is better" was used for "optimum is better" soil function [81, 82, 95].

$$
\operatorname{GNSLF}(Y)=\frac{1}{1+e^{-b(x-A)}},
$$

where $Y$ is the nonlinear score of the indicator value, $x$ is the indicator value, $A$ is the baseline value where the indicator score equals 0.5 , and $b$ is the slope.

2.7. Soil Quality Index Development. Three soil quality indexing methods were computed: the Additive Soil Quality Index (SQI-A), Weighted Additive Soil Quality Index (SQI-W), and Nemoro Soil Quality Index (SQI-N). Each soil quality method was applied for each soil quality indicator dataset.

In the Additive Soil Quality Index (SQI-A), the scores of the quality indicators were summed and divided by the dataset number of indicators $[15,108]$.

$$
\mathrm{SQI}-\mathrm{A}=\frac{\sum_{i=1}^{n} S_{i}}{n}
$$

where SQI-A is the soil quality index, $S_{i}$ is the linear or nonlinear indicator score value, and $n$ is the number of indicators of the dataset.

For the Weighted Additive Soil Quality Index (SQI-W), the score of each indicator was multiplied by the indicator weight and summed $([64,78,83])$.

$$
\mathrm{SQI}-\mathrm{W}=\sum_{i=1}^{n} W_{i} S_{i},
$$

where SQI-W is the weighted additive soil quality index, $W_{i}$ is the indicator weight, $S_{i}$ is the linear or nonlinear indicator score value, and $n$ is the number of indicators of the dataset.

The Nemoro Soil Quality Index (SQI-N) was calculated according to the indicator's minimum and average scores [108-110].

$$
\mathrm{SQI}-\mathrm{N}=\sqrt{\frac{S_{\text {iave }}^{2}+S_{\text {imin }}^{2}}{2}} \times \frac{n-1}{n},
$$

where SQI-N is the soil quality index, $S_{\text {iave }}$ is the indicator's score average, $S_{\text {imin }}$ is the linear or nonlinear indicator's score minimum, and $n$ is the number of indicators of the dataset.

2.8. Soil Quality Grade Classification. Each soil quality index range was classified into grades by applying Jenks's natural breaks optimization method [111]. Jenks's method is an iterative clustering method for determining the best clustering of values into different classes by reducing the variance within classes and maximizing the variance between classes [112]. Five grades were determined for each soil quality index: very high (grade I), high (grade II), moderate (grade III), low (grade IV), and very low (grade V). The grades are from the most suitable for plant growth to the most severe for plant growth. 
2.9. Soil Quality Index Comparison and Sensitivity. Direct comparison analyses of soil quality grades were used to evaluate the indices' performance by comparing the number of sampling sites where the soil quality index and indicator combinations had the same soil quality grade $[36,96,108]$. Soil quality indexing methods were also evaluated using sensitivity analysis $[88,113]$ by computing the ratio between the maximum and minimum soil quality index value for each scoring function using each soil and terrain indicators dataset selection methods. The soil quality indexing method with the higher index value of sensitivity is more preferable as this is sensitive to perplexity in management practices. Also, the linear relationship between the soil quality indices was examined by the correlation within indices, and the regression relation within the indicator methods was performed.

2.10. Soil Quality Index Spatial Distribution. The spatial distributions of soil quality index grades were developed by applying the Ordinary Kriging (OK) interpolation technique. For each soil quality index, the semivariogram models were generated using the following model parameters: model type, sill, range, and maximum and minimum neighbors. Eleven model types (circular, spherical, tetraspherical, pentaspherical, exponential, Gaussian, rational quadratic, hole effect, K-Bessel, J-Bessel, and stable) were examined for predicting the spatial distribution of soil quality indices. The accuracy of the predictive model is of greater importance as it is shown how well the spatial pattern of variation can be represented [114]. The best fitting semivariogram model with optimized parameters was selected by incorporating the cross-validation technique to obtain high interpolation accuracy. The cross-validation technique ensures the same probability of being validated against each data sample [115]. The output statistical parameters of the cross-validation technique determine the best and highly accurate prediction model for mapping soil quality indices [115].

2.11. Statistical Analyses. Soil indicators were examined for outliers using Quantile Range Outliers statistic with (0.01, $0.05,0.1$, and 0.15$)$ probabilities of the lower quantiles. The normalities of all indicators were examined using the Kolmogorov-Smirnov test and visual examination of histograms. The $\mathrm{pH}, \mathrm{OM}, \mathrm{BD}$, and $\mathrm{CEC}$ data were $\log$ transformed, EC was inverse transformed, and SAR, CCE, and ESP were square-root transformed to reduce the skew of their distributions. The relationship between soil and terrain indicators was examined by the Pearson correlation coefficient $(r)$. Bartlett's test of sphericity was conducted to examine whether the correlation matrix of the soil and terrain indicators is an orthogonal matrix or it diverges significantly from the identity matrix and there is a degree of redundancy between the indicators. The Kaiser-Meyer-Olkin Measure of Sampling Adequacy (MSA) was conducted to indicate whether factor analysis is likely to be appropriate and will gain distinct and reliable factors or not appropriate. The results of Bartlett's test and MSA will verify if factor analyses can interpret the structure of data and reduce the soil and terrain indicators to a minimum dataset. The statistical and multivariate analyses were performed using JMP pro 14 software for Windows [68]. Scoring and indexing were performed using Microsoft Excel software, ver. 2016 and geostatistical interpolation and mapping using ArcGIS Desktop 10.8 software [116].

\section{Results and Discussion}

3.1. Soil and Terrain Indicator Characteristics. The soil and terrain indicators related to soil quality were subjected to descriptive analyses (Table 2). The quantile range outlier's statistic indicated no outliers existed in soil and terrain indicator data. The elevation of the sampling sites ranged between -19 and $197 \mathrm{~m}$ above mean sea level. The Rlf, sand, Slp, $\mathrm{CaCO}_{3}$, and clay indicators showed high data dispersion indicating that the spatial variations of these soil indicators are large, while the other soil and terrain indicators are of weak spatial variation as they have low data dispersion.

The correlation analysis of soil physical and chemical indicators and terrain indicators revealed that there is a significant correlation in 35 of 136 soil and terrain indicator correlation pairs at a significant level of $p<0.05$ (Table 3). The highest positive correlations were between soil clay content against soil field capacity, available water holding capacity, and soil packing density where the correlation coefficient is greater than 0.90 . Also, the soil field capacity indicated a high positive correlation coefficient $(r>0.95)$ with available water holding capacity and soil packing density $(r>0.94)$. The highest negative correlation coefficients were obtained between sand and clay $(r>0.93)$, soil field capacity $(r>0.96)$, available water holding capacity $(r>0.99)$, and soil packing density $(r>0.93)$. It is also noted that soil organic matter indicator $(\mathrm{OM})$ has a moderate positive relationship with CEC (0.45) and a moderate negative relationship with BD $(-0.54)$ while it has no significant relationship with the soil salinity indicator (EC).

Bartlett's test of sphericity revealed that the soil and terrain indicator correlation coefficients are significantly different than the identity correlation matrix $(<0.05)$ and the indicators are not perfectly uncorrelated. The Kaiser-Meyer-Olkin Measure of Sampling Adequacy (MSA) revealed that the MSA value is above 0.6 and acceptable. This result of MSA indicates that there is a proportion of variance in soil and terrain indicators that might be caused by underlying factors. The Kaiser-Meyer-Olkin and Bartlett's test show that there is a high scope for data reduction with factor analyzing where the pattern of data structure in indicators can be interpreted.

3.2. Minimum Dataset Indicators. The analyses of the relationship between soil and terrain indicators revealed that there are noted redundancy and collinearity among indicators and there is a need to establish a minimum dataset for 
TABLE 2: Descriptive statistics of soil and terrain indicators.

\begin{tabular}{|c|c|c|c|c|c|c|c|}
\hline Indicator & Mean & SE & Min & $Q_{1}$ & Median & $Q_{3}$ & Max \\
\hline Sand & 81.09 & 0.39 & 65.00 & 76.00 & 80.00 & 85.00 & 99.87 \\
\hline Silt & 6.16 & 0.17 & 0.09 & 5.00 & 7.54 & 10.00 & 17.79 \\
\hline Clay & 8.51 & 0.28 & 0.04 & 8.00 & 12.00 & 15.00 & 26.00 \\
\hline $\mathrm{pH}$ & 7.38 & 0.02 & 7.00 & 7.16 & 7.24 & 7.50 & 8.20 \\
\hline $\mathrm{EC}$ & 2.63 & 0.10 & 0.05 & 2.02 & 2.96 & 3.86 & 13.14 \\
\hline $\mathrm{OM}$ & 0.22 & 0.01 & 0.01 & 0.14 & 0.21 & 0.37 & 1.50 \\
\hline ESP & 6.43 & 0.16 & 1.00 & 4.51 & 6.92 & 9.98 & 13.46 \\
\hline CEC & 2.13 & 0.10 & 0.02 & 1.46 & 2.32 & 3.16 & 11.71 \\
\hline $\mathrm{CaCO} 3$ & 1.95 & 0.13 & 0.04 & 1.44 & 2.63 & 4.20 & 17.22 \\
\hline FC & 10.95 & 0.23 & 2.89 & 9.54 & 12.39 & 15.02 & 24.63 \\
\hline AWHC & 5.40 & 0.06 & 2.86 & 4.89 & 5.60 & 6.35 & 8.61 \\
\hline $\mathrm{BD}$ & 1.59 & 0.00 & 1.41 & 1.59 & 1.61 & 1.62 & 1.63 \\
\hline PD & 1.69 & 0.00 & 1.42 & 1.67 & 1.72 & 1.75 & 1.84 \\
\hline Slp & 5.90 & 0.22 & 0.54 & 4.09 & 6.32 & 9.89 & 24.11 \\
\hline Rlf & 14.94 & 0.28 & 3.00 & 12.00 & 15.00 & 19.00 & 44.00 \\
\hline TWI & 7.79 & 0.09 & 5.52 & 6.82 & 7.24 & 8.33 & 11.70 \\
\hline \multicolumn{4}{|c|}{$\begin{array}{l}\text { Kaiser-Meyer-Olkin measure } \\
\text { of sampling adequacy }\end{array}$} & MSA & 0.74 & & \\
\hline \multicolumn{2}{|c|}{$\begin{array}{l}\text { Bartlett's test of } \\
\text { sphericity }\end{array}$} & \multicolumn{3}{|c|}{ Approx. chi-square } & 16428.05 & & \\
\hline & & & & Df & 120 & & \\
\hline & & & & Sig. & 0.00 & & \\
\hline
\end{tabular}

Mean is represented by geometric mean, SE is the standard error, Min is the minimum value, Max is the maximum value, $Q_{1}$ and $Q_{3}$ are the lower and upper quartiles, respectively.

the process of soil quality assessment by eliminating some indicators performing factor analyses.

The results of factor analyses on standardized soil and terrain indicators values revealed that the first five factors accounted for $78.76 \%$ of indicator variability with eigenvalue greater than 1 (Table 4). Thus, the first five factor analyses were retained and the other factors with eigenvalue less than 1 were excluded as the indicators may explain more variance than those excluded factors [117].

The retained factors explain more than $97 \%$ of the variance for sand and AWHC in indicators (Table 5); more than $91 \%$ for PD, FC, BD, and clay indicators; more than $71 \%$ for OM, CaCO3, Slp, CEC, pH, Rlf, and EC indicators; and more than $55 \%$ for ESP and silt indicators. The TWI indicator was the least important indicator due to its lowest communality estimate (less than $28 \%$ variance) as the higher communality estimates procure more preference upon the lower ones.

The representative soil and terrain indicators for soil quality were chosen based on their relationship with the retained factors as the eigenvalues were the criteria magnitude for the interpretation (Table 5). In the first factor, eight quality indicator factor loads are more than 0.7 which are sand, silt, clay, $\mathrm{pH}, \mathrm{FC}, \mathrm{AWHC}, \mathrm{BD}$, and $\mathrm{PD}$. In the second factor, only the $\mathrm{OM}$ indicator is of high weight variable accounting for 0.92 of variation. In the third factor, slp and rlf indicators' factor loads are of more than 0.85. CEC and $\mathrm{CaCO}_{3}$ indicators are more than 0.67 in the fourth factor. The fifth factor contains only EC and ESP indicator factor loads of more than 0.79 . The soil and terrain quality indicators were grouped according to that criterion into five groups (Table 6).
The first factor explained about $41 \%$ of the total variance with high positive loadings from AWHC, FC, clay, PD, and $\mathrm{BD}$ indicators $(>0.85)$ and high negative loading from the sand indicator $(-0.99)$. The moderate positive loadings were from silt (0.74) and negative loading from $\mathrm{pH}(-0.74)$ indicators. The significant correlation coefficients among sand, silt, clay, $\mathrm{pH}, \mathrm{FC}, \mathrm{AWHC}, \mathrm{BD}$, and PD indicators influenced the factors' loading values. The first factor expresses the influence of soil texture on hydraulic soil properties as it clarifies the soil moisture and water flow properties.

The second factor explained about $10 \%$ of the total variance with high positive loading from the $\mathrm{OM}$ indicator (0.92) and moderate positive loading from CEC (0.55). The second factor had also moderate negative loading from the $\mathrm{BD}$ indicator $(-0.47)$ and moderate positive loading from the $\mathrm{pH}$ indicator (0.35). The second factor expresses the effect of soil organic matter content on bulk density and soil cation exchange capacity.

The third factor explained about $9.6 \%$ of the total variance with high positive loading from Slp (0.88) and Rlf $(0.85)$ indicators. This factor is a proxy of surface as it clearly shows the effect of terrain on soil properties as they significantly correlated.

The fourth factor explained about $8 \%$ of the total variance with high positive loading from the $\mathrm{CaCO}_{3}$ indicator (0.88) and moderate positive loading from CEC (0.67) indicators. Also, the fourth factor has negative moderate loading from the TWI indicator $(-0.45)$ resulting from significant correlations among $\mathrm{CaCO}_{3}, \mathrm{CEC}$, and TWI. The fourth factor expresses the interaction between $\mathrm{CaCO}_{3}$, CEC, and soil wetness as where wetness occurs, the calcium salts readily dissolved and interfere with soil exchangeable cations $[118,119]$ and the presence of calcium carbonates is associated with cascading changes in soil biogeochemistry [120].

The fifth factor explained about $8.8 \%$ of the total variance with high positive loading from the EC indicator $(0.81)$ and ESP (0.79). This factor represents salinity characteristics.

The Norm analyses (Table 6) revealed that, from eight quality indicators in the first group, only the AWHC indicator is with the highest Norm value. The OM indicator is the only indicator in the second group, while Slp, CEC, and EC indicators are the highest in the third, fourth, and fifth group, respectively. According to these results, the minimum dataset indicators include five soil and terrain quality indicators which are AWHC, OM, Slp, CEC, and EC indicators.

3.3. Soil Quality Assessment. The soil quality indices were calculated and ranked for each method. The classification criteria for the different calculated soil quality indices based on the different scoring techniques show variation between quality methods ( $\mathrm{A}, \mathrm{W}$, and $\mathrm{N}$ ), but there are slight similarities between each quality scoring technique for the different quality calculation methods. The threshold grade values of the scoring methods for each soil quality method were nearly the same threshold range values although the threshold grades values for the different scoring methods were not consistent. 
TABLE 3: Correlation matrix for measured soil and terrain attributes $(n=397)$.

\begin{tabular}{|c|c|c|c|c|c|c|c|c|c|c|c|c|c|c|c|}
\hline & Sand & Silt & Clay & $\mathrm{pH}$ & $\mathrm{EC}$ & $\mathrm{OM}$ & ESP & CEC & $\mathrm{CaCO}_{3}$ & $\mathrm{FC}$ & AWHC & $\mathrm{BD}$ & $\mathrm{PD}$ & Slp & Rlf \\
\hline Sand & 1.00 & & & & & & & & & & & & & & \\
\hline Silt & -0.79 & 1.00 & & & & & & & & & & & & & \\
\hline Clay & -0.93 & 0.51 & 1.00 & & & & & & & & & & & & \\
\hline $\mathrm{pH}$ & 0.70 & -0.44 & -0.72 & 1.00 & & & & & & & & & & & \\
\hline EC & -0.18 & 0.13 & 0.18 & -0.27 & 1.00 & & & & & & & & & & \\
\hline $\mathrm{OM}$ & 0.08 & -0.09 & -0.06 & 0.31 & -0.03 & 1.00 & & & & & & & & & \\
\hline ESP & -0.05 & 0.00 & 0.06 & -0.21 & 0.35 & -0.20 & 1.00 & & & & & & & & \\
\hline CEC & -0.04 & 0.03 & 0.04 & 0.27 & 0.02 & 0.45 & -0.08 & 1.00 & & & & & & & \\
\hline $\mathrm{CaCO} 3$ & 0.07 & -0.05 & -0.06 & 0.11 & -0.04 & 0.15 & -0.07 & 0.49 & 1.00 & & & & & & \\
\hline $\mathrm{FC}$ & -0.96 & 0.59 & 0.99 & -0.69 & 0.18 & 0.01 & 0.03 & 0.07 & -0.06 & 1.00 & & & & & \\
\hline AWHC & -0.99 & 0.80 & 0.91 & -0.64 & 0.18 & 0.02 & 0.00 & 0.09 & -0.06 & 0.95 & 1.00 & & & & \\
\hline $\mathrm{BD}$ & -0.83 & 0.59 & 0.81 & -0.78 & 0.16 & -0.54 & 0.17 & -0.16 & -0.10 & 0.78 & 0.74 & 1.00 & & & \\
\hline $\mathrm{PD}$ & -0.93 & 0.57 & 0.96 & -0.79 & 0.18 & -0.31 & 0.12 & -0.06 & -0.09 & 0.94 & 0.87 & 0.94 & 1.00 & & \\
\hline Slp & 0.03 & -0.04 & -0.02 & 0.04 & 0.00 & -0.01 & -0.06 & -0.03 & -0.01 & -0.02 & -0.03 & -0.03 & -0.03 & 1.00 & \\
\hline Rlf & 0.04 & -0.01 & -0.04 & 0.10 & -0.02 & 0.08 & -0.11 & 0.08 & 0.06 & -0.03 & -0.02 & -0.09 & -0.06 & 0.51 & 1.00 \\
\hline TWI & 0.06 & -0.13 & -0.01 & 0.00 & 0.06 & -0.13 & 0.09 & -0.14 & -0.12 & -0.03 & -0.08 & 0.04 & 0.02 & -0.14 & -0.04 \\
\hline
\end{tabular}

EC, electrical conductivity $\left(\mathrm{dS} \mathrm{m}^{1}\right)$; SOM, soil organic matter (\%); ESP, exchangeable sodium percent (\%); $\mathrm{CEC}$, cation exchange capacity $\left(\mathrm{cmol} \mathrm{kg}^{1}\right) ; \mathrm{CaCO}_{3}$, calcium carbonates content (\%); FC, field capacity water content (\%); AWHC, available water holding capacity (\%); BD, soil bulk density; PD, soil packing density; Slp, slope (\%); Rlf, relief (m), TWI, topographic wetness index.

TABle 4: Eigenvalues, proportions and cumulative variance explained by factor analysis using a correlation matrix of standardized soil and terrain indicator data.

\begin{tabular}{lcccc}
\hline Factor & Eigenvalue & Difference & Proportion & Cumulative \\
\hline 1 & 6.72 & 6.55 & 40.94 & 40.94 \\
2 & 2.09 & 1.65 & 10.34 & 51.28 \\
3 & 1.52 & 1.53 & 9.58 & 60.86 \\
4 & 1.28 & 1.45 & 9.08 & 69.94 \\
5 & 1.00 & 1.41 & 8.82 & 78.76 \\
\hline
\end{tabular}

The cross validation for comparing the different selected interpolation ordinary kriging models identified the exponential predictive model as the best accurate model for representing the spatial distribution of soil quality indices other than the other predictive models (data not shown). The distribution of soil quality indices (Table 7) shows a degree of pattern similarity between soil quality indices across the different quality grouping types with indicators scoring functions.

Soil quality grade III (moderate) is mainly the largest area percentage proportion in most soil quality indexing methods and scoring functions across the three soil quality datasets groups (TDS, MDS, and EDS) followed by grade II (High), grade IV (low), grade I (very high), and grade V (very low), respectively. A little part of the study area is for grades I (very high) and V (very low) with area percentage coverage. Soil quality grade III (moderate) on average accounts for $40 \%$ of the study area, and soil quality grade II (high) accounts for $30 \%$ of the study area, while the rest of soil quality grades (I, IV, and V) accounts for $20 \%$ of the study area. The disparities between the spatial distribution of soil qualities across indexing methods and scoring functions are of no large distribution disparity.

3.4. Comparison of Indices. Sensitivity analyses for soil quality indices showed that the soil quality grouping type of the indicator dataset, quality indexing method, and indicators scoring function are impacting the soil quality values in the study area (Table 8). The LLSF linear scoring function is larger sensitive to the variation in soil quality compared with other sensitivities for all indicator grouping types, soil quality methods, and scoring functions specially with the minimum dataset grouping type while SNLSF nonlinear scoring function is the less sensitive to soil quality variation.

Sensitivity analysis showed that both indexing and dataset selection methods influenced the SQI values for the various soil quality values. Thus, the analyses emphasize that the indicator dataset grouping type, the indexing method, and scoring function could assist in the evaluation of the soil condition status in the study area. The Linear Scoring Functions (LSFs) disclosed more soil quality variations further than Nonlinear Scoring Functions (NLSFs). The resulted sensitivity analyses agree with the results in [89] where the Linear Scoring functions (LSFs) are more favorable than Nonlinear Scoring Functions (NLSFs) in evaluating soil quality indices. It is in contrast with the work in $[15,88]$ where it was reported that Nonlinear Scoring Functions (NLSFs) are favorable in studies with one linear and one nonlinear scoring functions, and their sensitivity was not evaluated [89].

The linear relationships between the indicator datasets with different scoring functions and indices models (Table 9) showed a significant correlation $(P<0.05)$. The values of the linear relationships between MDS and TDS datasets are higher than the values of the linear relationships between EDS and TDS datasets across linear and nonlinear scoring functions and index models. The values of the linear relationships between TDS and MDS datasets for the weighted additive quality index are higher than the values of the linear relationship for additive and Nemoro indexing methods for all the linear and nonlinear scoring functions. In contrast, the linear relationships between the TDS and EDS datasets for the weighted additive quality index are mostly lower than 
TABLE 5: Proportion of variance using varimax rotation and communality estimates for soil and terrain indicators for each of the retained factors.

\begin{tabular}{lcccccc}
\hline Indicator & Factor 1 & Factor 2 & Factor 3 & Factor 4 & Factor 5 & Communality estimates \\
\hline Sand & -0.99 & -0.02 & 0.01 & -0.01 & -0.03 & 0.99 \\
Silt & 0.74 & 0.02 & 0.00 & 0.05 & -0.05 & 0.55 \\
Clay & 0.95 & 0.01 & -0.01 & -0.01 & 0.07 & 0.91 \\
pH & -0.74 & 0.35 & 0.04 & 0.10 & -0.22 & 0.74 \\
EC & 0.17 & 0.13 & 0.05 & -0.07 & 0.81 & 0.71 \\
OM & -0.09 & 0.92 & 0.03 & 0.09 & -0.08 & 0.87 \\
ESP & 0.00 & -0.23 & -0.09 & -0.02 & 0.79 & 0.68 \\
CEC & 0.03 & 0.55 & -0.03 & 0.67 & 0.07 & 0.75 \\
CaCO3 & -0.08 & 0.03 & -0.05 & 0.88 & 0.04 & 0.96 \\
FC & 0.97 & 0.09 & -0.01 & -0.01 & 0.05 & 0.97 \\
AWHC & 0.98 & 0.13 & 0.00 & 0.02 & 0.00 & 0.95 \\
BD & 0.85 & -0.47 & -0.04 & 0.00 & 0.10 & 0.96 \\
PD & 0.95 & -0.23 & -0.02 & -0.01 & 0.09 & 0.78 \\
Slp & -0.02 & -0.07 & 0.88 & 0.02 & -0.02 & 0.73 \\
Rlf & -0.03 & 0.09 & 0.85 & 0.06 & -0.02 & 0.21 \\
TWI & -0.07 & 0.01 & -0.17 & -0.45 & 0.21 \\
\hline
\end{tabular}

TABLE 6: Included soil and terrain indicators in the minimum dataset from representative indicators.

\begin{tabular}{lccccccccc}
\hline Group & Indicator & Vector norm & \multicolumn{2}{c}{$\begin{array}{c}\text { Coefficient of } \\
\text { determination }\end{array}$} & \multicolumn{2}{c}{$\begin{array}{c}\text { Standard normal } \\
\text { transformation }\end{array}$} & Indicator value & Included \\
& & & NDVI & Elev & Norm & NDVI & Elev & \\
\hline 1 & Sand & 2.57 & 0.18 & 0.14 & 1.00 & 0.80 & 1.00 & 2.80 \\
1 & Silt & 1.91 & 0.10 & 0.10 & 0.74 & 0.43 & 0.74 & 1.91 & No \\
1 & Clay & 2.47 & 0.17 & 0.11 & 0.96 & 0.74 & 0.96 & 2.66 & No \\
1 & pH & 2.01 & 0.02 & 0.01 & 0.78 & 0.11 & 0.78 & 1.67 & No \\
1 & FC & 2.52 & 0.20 & 0.14 & 0.98 & 0.90 & 0.98 & 2.86 & No \\
1 & AWHC & 2.54 & 0.23 & 0.17 & 0.99 & 1.00 & 0.99 & 2.97 & Yes \\
1 & BD & 2.30 & 0.02 & 0.02 & 0.89 & 0.09 & 0.89 & 1.87 & No \\
1 & PD & 2.48 & 0.09 & 0.07 & 0.96 & 0.39 & 0.96 & 2.32 & No \\
2 & OM & 1.36 & 0.09 & 0.02 & 0.53 & 0.38 & 0.53 & 1.43 & Yes \\
3 & Slp & 1.09 & 0.00 & 0.01 & 0.42 & 0.02 & 0.42 & 0.86 & Yes \\
3 & Rlf & 1.06 & 0.00 & 0.01 & 0.41 & 0.01 & 0.41 & 0.83 \\
4 & CEC & 1.10 & 0.00 & 0.01 & 0.43 & 0.02 & 0.43 & 0.87 \\
4 & CaCO3 & 1.02 & 0.00 & 0.00 & 0.40 & 0.01 & 0.40 & 0.80 & No \\
5 & EC & 0.95 & 0.01 & 0.00 & 0.37 & 0.03 & 0.37 & 0.77 \\
5 & ESP & 0.86 & 0.01 & 0.06 & 0.33 & 0.02 & 0.33 & 0.69 \\
\hline
\end{tabular}

the linear relationship values for additive and Nemoro indexing methods except for LLSF and HLSF linear scoring functions. The additive and weighted additive quality models' values are quite similar for the scoring function type between the datasets.

The MDS weighted additive soil quality index grades with the LLSF scoring technique represented more soil quality variation with $R^{2}=0.90$ than the other soil qualities indices (Figure 2) (other spatial distributions of the other soil quality methods' grade scoring techniques are not shown).

The results of sensitivity analyses and linear relationships between the indicator datasets with different scoring functions and index models point out that the MDS indicator dataset with the weighted additive quality model explains the soil quality indicators with the different quality models other than TDS and EDS indicator datasets and could assist in monitoring the temporal changes in soil quality of the region due to the increased agricultural development. These findings agreed with the findings of the other studies in arid and semiarid regions $[36,110,121]$ where the MDS dataset with the weighted additive soil quality model is better for evaluating soil quality as the weighted additive model represents the indicators of the soil quality rather than the additive and Nemoro quality models [96, 108] and factor analyses provide the most representing indicators and the weights that differentiate the relative importance of soil quality indicators for evaluating soil quality $[63,107]$. 
TABLE 7: Distribution of index area grades across different soil quality index methods.

\begin{tabular}{|c|c|c|c|c|c|c|c|}
\hline \multirow{2}{*}{ Indicator datasets } & \multirow{2}{*}{ SQI model } & \multirow{2}{*}{ Statistic } & \multicolumn{5}{|c|}{ Soil quality grade } \\
\hline & & & I (very high) & II (high) & III (moderate) & IV (low) & $\mathrm{V}$ (very low) \\
\hline \multirow{9}{*}{ TDS } & \multirow{3}{*}{ SQI-A } & Min & 0.00 & 13.81 & 29.73 & 12.34 & 0.12 \\
\hline & & $\operatorname{Max}$ & 3.52 & 31.00 & 44.69 & 35.82 & 3.53 \\
\hline & & Mean & 1.77 & 23.70 & 39.69 & 23.61 & 1.52 \\
\hline & \multirow{3}{*}{ SQI-W } & Min & 2.80 & 18.00 & 37.77 & 3.31 & 0.00 \\
\hline & & $\operatorname{Max}$ & 5.75 & 42.19 & 49.72 & 18.87 & 0.44 \\
\hline & & Mean & 4.31 & 35.13 & 42.00 & 8.77 & 0.09 \\
\hline & \multirow{3}{*}{ SQI-N } & Min & 0.00 & 16.89 & 36.26 & 12.11 & 0.11 \\
\hline & & $\operatorname{Max}$ & 2.84 & 25.32 & 51.37 & 28.08 & 1.52 \\
\hline & & Mean & 0.84 & 22.02 & 46.64 & 19.88 & 0.91 \\
\hline \multirow{9}{*}{ MDS } & \multirow{3}{*}{ SQI-A } & Min & 0.00 & 13.93 & 19.48 & 0.17 & 0.00 \\
\hline & & Max & 6.08 & 63.00 & 46.89 & 33.35 & 0.17 \\
\hline & & Mean & 2.44 & 45.74 & 33.82 & 8.26 & 0.03 \\
\hline & \multirow{3}{*}{ SQI-W } & Min & 0.01 & 12.04 & 29.75 & 0.40 & 0.00 \\
\hline & & $\operatorname{Max}$ & 3.12 & 58.46 & 46.62 & 36.55 & 0.08 \\
\hline & & Mean & 1.00 & 41.22 & 38.09 & 9.96 & 0.02 \\
\hline & \multirow{3}{*}{ SQI-N } & Min & 0.00 & 1.94 & 18.28 & 0.00 & 0.00 \\
\hline & & Max & 3.94 & 58.32 & 47.27 & 67.42 & 2.65 \\
\hline & & Mean & 1.53 & 37.40 & 34.99 & 15.83 & 0.55 \\
\hline \multirow{9}{*}{ EDS } & \multirow{3}{*}{ SQI-A } & Min & 0.00 & 13.20 & 31.68 & 13.11 & 0.00 \\
\hline & & $\operatorname{Max}$ & 5.88 & 28.84 & 46.52 & 37.50 & 4.04 \\
\hline & & Mean & 1.57 & 21.78 & 40.55 & 25.10 & 1.30 \\
\hline & \multirow{3}{*}{ SQI-W } & Min & 0.00 & 12.54 & 37.38 & 12.64 & 0.00 \\
\hline & & $\operatorname{Max}$ & 6.78 & 28.33 & 47.81 & 28.81 & 6.08 \\
\hline & & Mean & 1.78 & 20.37 & 42.97 & 22.61 & 2.56 \\
\hline & \multirow{3}{*}{ SQI-N } & Min & 0.00 & 9.14 & 38.78 & 16.33 & 0.00 \\
\hline & & Max & 5.67 & 31.15 & 53.09 & 36.11 & 3.12 \\
\hline & & Mean & 1.43 & 22.63 & 43.12 & 22.41 & 0.70 \\
\hline
\end{tabular}

TABLE 8: Sensitivity analyses between indicator datasets, models, and scoring functions.

\begin{tabular}{|c|c|c|c|c|c|c|}
\hline \multirow{2}{*}{ Indicator datasets } & \multirow{2}{*}{ SQI model } & \multicolumn{3}{|c|}{ LSF } & \multicolumn{2}{|c|}{ NLSF } \\
\hline & & LLSF & HLSF & GLSF & SNLSF & GNLSF \\
\hline \multirow{3}{*}{ TDS } & SQI-A & 2.48 & 1.77 & 1.62 & 1.39 & 2.14 \\
\hline & SQI-W & 3.68 & 3.19 & 1.85 & 1.53 & 2.68 \\
\hline & SQI-N & 2.52 & 1.89 & 1.82 & 1.69 & 2.14 \\
\hline \multirow{3}{*}{ MDS } & SQI-A & 4.66 & 3.13 & 3.31 & 2.52 & 2.63 \\
\hline & SQI-W & 4.87 & 4.43 & 3.49 & 2.54 & 3.11 \\
\hline & SQI-N & 4.44 & 3.43 & 3.23 & 3.18 & 3.52 \\
\hline \multirow{3}{*}{ EDS } & SQI-A & 3.61 & 2.58 & 2.21 & 2.02 & 3.38 \\
\hline & SQI-W & 3.94 & 3.72 & 2.46 & 2.42 & 2.83 \\
\hline & SQI-N & 3.38 & 3.06 & 3.28 & 2.19 & 3.09 \\
\hline
\end{tabular}

TAвLE 9: The linear relationships between indicator datasets with different scoring functions.

\begin{tabular}{|c|c|c|c|c|c|c|c|c|c|}
\hline SQI & Scoring method & SQI model & Relationship & $R^{2}$ & SQI & Scoring method & SQI model & Relationship & $R^{2}$ \\
\hline \multirow{15}{*}{ TDS-MDS } & \multirow{4}{*}{ LLSF } & SQI-A & $0.4586 x+0.3132$ & 0.54 & & \multirow{3}{*}{ LLSF } & SQI-A & $0.4634 x+0.2378$ & 0.30 \\
\hline & & SQI-W & $0.895 x+0.0108$ & 0.90 & & & SQI-W & $1.0574 x-0.1869$ & 0.64 \\
\hline & & SQI-N & $0.5027 x+0.2111$ & 0.51 & & & SQI-N & $0.4161 x+0.1865$ & 0.23 \\
\hline & & SQI-A & $0.3592 x+0.2888$ & 0.46 & & \multirow{3}{*}{ HLSF } & SQI-A & $0.4433 x+0.2045$ & 0.43 \\
\hline & \multirow[t]{2}{*}{ HLSF } & SQI-W & $0.61 x+0.0661$ & 0.62 & & & SQI-W & $0.6876 x-0.0129$ & 0.50 \\
\hline & & SQI-N & $0.2621 x+0.1909$ & 0.49 & & & SQI-N & $0.5026 x+0.1393$ & 0.42 \\
\hline & \multirow[t]{3}{*}{ GLSF } & SQI-A & $0.3725 x+0.2409$ & 0.42 & & \multirow{3}{*}{ GLSF } & SQI-A & $0.4703 x+0.15$ & 0.39 \\
\hline & & SQI-W & $0.4989 x+0.0665$ & 0.51 & TDS-EDS & & SQI-W & $0.5191 x+0.0143$ & 0.31 \\
\hline & & SQI-N & $0.4239 x+0.161$ & 0.41 & & & SQI-N & $0.5284 x+0.0997$ & 0.39 \\
\hline & \multirow[t]{3}{*}{ SNLSF } & SQI-A & $0.3487 x+0.321$ & 0.42 & & \multirow{3}{*}{ SNLSF } & SQI-A & $0.3989 x+0.2996$ & 0.50 \\
\hline & & SQI-W & $0.4977 x+0.1489$ & 0.48 & & & SQI-W & $0.4134 x+0.1926$ & 0.32 \\
\hline & & SQI-N & $0.3606 x+0.2319$ & 0.39 & & & SQI-N & $0.4391 x+0.2081$ & 0.50 \\
\hline & \multirow[t]{3}{*}{ GNLSF } & SQI-A & $0.3088 x+0.2933$ & 0.24 & & \multirow{3}{*}{ GNLSF } & SQI-A & $0.3612 x+0.2166$ & 0.44 \\
\hline & & SQI-W & $0.3884 x+0.151$ & 0.39 & & & SQI-W & $0.1992 x+0.185$ & 0.11 \\
\hline & & SQI-N & $0.3341 x+0.1981$ & 0.24 & & & SQI-N & $0.3517 x+0.1559$ & 0.42 \\
\hline
\end{tabular}




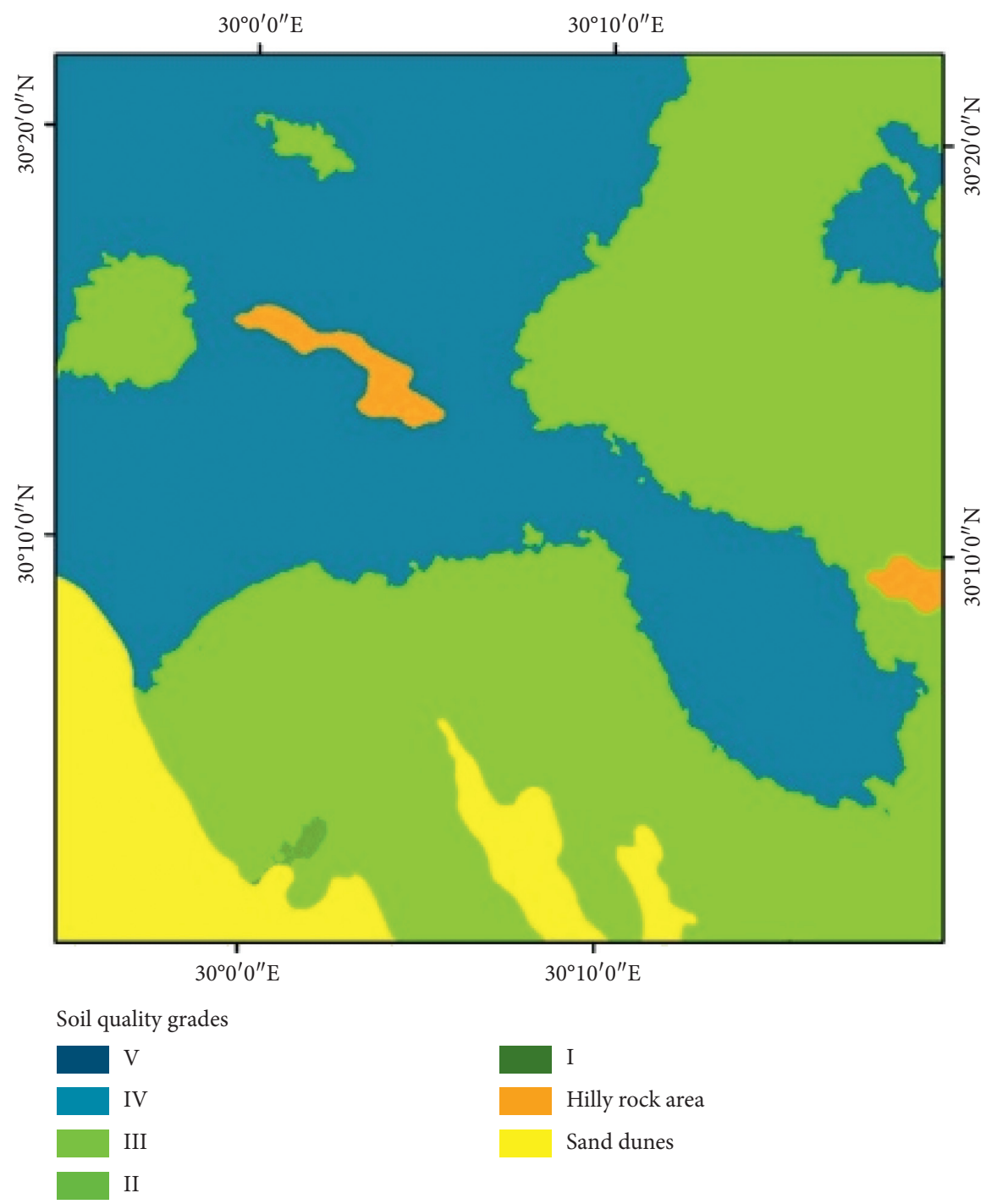

FIGURE 2: Spatial distribution of MDS weighted additive soil quality index with the LLSF scoring technique.

\section{Conclusions}

The objectives of this study were to (1) assess the soil quality using three types of indicator datasets (TDS, MDS, and EDS), three types of linear scoring functions, two types of nonlinear scoring functions, and three soil quality index models (additive, weighted additive, and Nemoro quality indices) and (2) find the most suitable indicator method and soil quality index model for the studied region with sensitivity and linear relationship statistical analyses.

The findings of the study indicate the following:

(i) Factor analyses are an efficient tool to reduce the number of quality indicators for soil quality assessment, thus reducing the time and cost of sampling and analyses; also, it may improve soil quality assessment by increasing the sampling density. Exterior environmental variables are commensurate directly to soil quality. Factor analyses and exterior environmental variables identified five soil and terrain indicators, AWHC, OM, Slp, CEC, and EC indicators, to be included in the MDS dataset.

(ii) The linear scoring functions are more favorable than nonlinear scoring functions in reflecting the soil system functions. Although there was a variation between soil quality models ( $\mathrm{A}, \mathrm{W}$, and $\mathrm{N}$ ) based on the different scoring functions, for each scoring function, there were slight similarities across the quality models.

(iii) Grade III (moderate) soil quality grade is mainly the largest area percentage proportion across the three soil quality dataset groups (TDS, MDS, and EDS). The distribution disparity between resulted soil qualities is low with a degree of pattern similarity. 
(iv) The MDS indicator dataset derived from factor analyses with the weighted additive quality model and LLSF scoring function was the most sensitive to assess soil quality as it is suitable to represent the TDS and explain the soil quality indicators.

Based on the study findings, the researchers conclude that the selection of a minimum dataset of quality indicators in addition to inexpensive ancillary data is more beneficial, especially using remote sensing data and digital elevation models, for representing a sufficient soil quality index than using a more complex dataset. Moreover, the MDS approach is more advantageous in Egypt as a developing country where the requirements for soil quality assessment must be unpretentious and inexpensive to be adopted. The studied area is under reclamation and cultivated during the last two decades as a directive by the country to increase the agricultural areas and meet the increasing food requirements. Land degradation processes may be triggered as long-term cultivation continued coupled with improper land utilization. According to that, the results of the study could be significantly used as a starting strategy for future research to monitor the temporal changes in soil quality and utilization planning.

\section{Data Availability}

The data used to support the findings of this study are as follows: the Landsat 8 satellite image was used to calculate the normalized difference vegetation index and freely downloaded from earthexplorer.usgs.gov. The shuttle radar topography mission (SRTM) image was used to obtain the surface parametric information used in the study and freely downloaded from earthexplorer.usgs.gov. The soil data for the study are the result of field survey and laboratory analyses funded by and part of the project Monitoring and mapping of encroachments on the state's lands and establishment of the information system of land and water resources in Wadi ElNatrun, Beheira Governorate, Project no. 0570/NC/GEN/2018. The data will be copyrighted by the project and can be made available based on the reasonable request of the publisher or any interested body.

\section{Conflicts of Interest}

The authors declare no conflicts of interest regarding the publication of this paper.

\section{Acknowledgments}

The project entitled Monitoring and mapping of encroachments on the state's lands and establishment of the information system of land and water resources in Wadi ElNatrun, Beheira Governorate, financially supported the study and provided all necessary facilities during the fieldwork, Project no. 0570/NC/GEN/2018. The authors would like to thank the Faculty of Agriculture, Beni Suef University, Egypt, for laboratory analysis. The authors would like to thank Abutaleb, Kh., and Farg E. from the National Authority for Remote Sensing and Space Sciences, Cairo, Egypt, for their assistance in the field work.

\section{References}

[1] J. A. Foley, N. Ramankutty, K. A. Brauman et al., "Solutions for a cultivated planet," Nature, vol. 478, no. 7369, pp. 337-342, 2011.

[2] M. Satoh and S. Aboulroos, Irrigated Agriculture in Egypt: Past, Present and Future, Springer International Publishing, Cham, Switzerland, 2017.

[3] J. Doran, M. Sarrantonio, and M. Liebig, "Soil health and sustainability," Advances in Agronomy, vol. 56, pp. 1-54, 1996.

[4] S. S. Andrews and C. R. Carroll, "Designing a soil quality assessment tool for sustainable agroecosystem management," Ecological Applications, vol. 11, no. 6, pp. 1573-1585, 2001.

[5] W. E. Larson and F. J. Pierce, "The dynamics of soil quality as a measure of sustainable management," in Defining Soil Quality for Sustainable Environment, J. W. Doran, D. G. Coleman, D. F. Bezddick, and B. A. Stewart, Eds., Soil Science Society of America, Madison, WI, USA, pp. 37-52, 1994.

[6] A. Desbiez, R. Matthews, B. Tripathi, and J. Ellis-Jones, "Perceptions and assessment of soil fertility by farmers in the mid-hills of Nepal," Agriculture, Ecosystems \& Environment, vol. 103, no. 1, pp. 191-206, 2004.

[7] S. Arslan, "Assessment of groundwater and soil quality for agricultural purposes in Kopruoren basin, Kutahya, Turkey," Journal of African Earth Sciences, vol. 131, pp. 1-13, 2017.

[8] J. Cheng, C. Ding, X. Li, T. Zhang, and X. Wang, "Soil quality evaluation for navel orange production systems in central subtropical China," Soil and Tillage Research, vol. 155, pp. 225-232, 2016.

[9] S. Firdous, S. Begum, and A. Yasmin, “Assessment of soil quality parameters using multivariate analysis in the Rawal Lake watershed," Environmental Monitoring and Assessment, vol. 188, no. 9, 533 pages, 2016.

[10] Y. Lin, H. Deng, K. Du et al., "Soil quality assessment in different climate zones of China's Wenchuan earthquake affected region," Soil and Tillage Research, vol. 165, pp. 315-324, 2017.

[11] L. C. Gray and P. Morant, "Reconciling indigenous knowledge with scientific assessment of soil fertility changes in southwestern Burkina Faso," Geoderma, vol. 111, no. 3-4, pp. 425-437, 2003.

[12] Y. Yageta, H. Osbahr, Y. Morimoto, and J. Clark, "Comparing farmers' qualitative evaluation of soil fertility with quantitative soil fertility indicators in Kitui County, Kenya," Geoderma, vol. 344, pp. 153-163, 2019.

[13] A. W. Wawire, Á. Csorba, E. Kovács, F. S. Mairura, J. A. Tóth, and E. Michéli, "Comparing farmers' soil fertility knowledge systems and scientific assessment in Upper Eastern Kenya," Geoderma, vol. 396, Article ID 115090, 2021.

[14] M. G. Kibblewhite, K. Ritz, and M. J. Swift, "Soil health in agricultural systems," Philosophical Transactions of the Royal Society B: Biological Sciences, vol. 363, no. 1492, pp. 685-701, 2008.

[15] S. S. Andrews, D. L. Karlen, and J. P. Mitchell, “A comparison of soil quality indexing methods for vegetable production systems in Northern California," Agriculture, Ecosystems \& Environment, vol. 90, no. 1, pp. 25-45, 2002.

[16] A. K. Bhardwaj, P. Jasrotia, S. K. Hamilton, and G. P. Robertson, "Ecological management of intensively cropped agro-ecosystems improves soil quality with 
sustained productivity," Agriculture, Ecosystems \& Environment, vol. 140, no. 3-4, pp. 419-429, 2011.

[17] M. Omer, O. J. Idowu, C. W. Brungard, A. L. Ulery, B. Adedokun, and N. Mcmillan, "Visible near-infrared reflectance and laser-induced breakdown spectroscopy for estimating soil quality in arid and semiarid agroecosystems," Soil Systems, vol. 4, no. 3, 42 pages, 2020.

[18] M. Cherubin, C. Tormena, and D. Karlen, "Soil quality evaluation using the soil management assessment framework (SMAF) in Brazilian oxisols with contrasting texture," Soil Use and Management, Revista Brasileira de Ciência do Solo, vol. 41, 2017.

[19] J. M. Mirás-Avalos, M. Fandiño, B. J. Rey, J. Dafonte, and J. J. Cancela, "Zoning of a newly-planted vineyard: spatial variability of physico-chemical soil properties," Soil Systems, vol. 4, no. 4, 62 pages, 2020.

[20] M. Castellini, L. Giglio, and F. Modugno, "Sampled soil volume effect on soil physical quality determination: a case study on conventional tillage and No-tillage of the soil under winter wheat," Soil Systems, vol. 4, no. 4, 72 pages, 2020.

[21] M. Jiang, L. Xu, X. Chen, H. Zhu, and H. Fan, "Soil quality assessment based on a minimum data set: a case study of a county in the typical river Delta wetlands," Sustainability, vol. 12, no. 21, 9033 pages, 2020.

[22] A. K. Fine, H. M. van Es, and R. R. Schindelbeck, "Statistics, scoring functions, and regional analysis of a comprehensive soil health database," Soil Science Society of America Journal, vol. 81, no. 3, pp. 589-601, 2017.

[23] A. Mukherjee and R. Lal, "Comparison of soil quality index using three methods," PLoS One, vol. 9, no. 8, Article ID e105981, 2014.

[24] G. B. Tesfahunegn, "Soil quality assessment strategies for evaluating soil degradation in northern Ethiopia," Applied and Environmental Soil Science, vol. 2014, Article ID 646502, 14 pages, 2014.

[25] J. W. Doran and T. B. Parkin, "Quantitative indicators of soil quality: a minimum data set," Methods for Assessing Soil Quality, vol. 4937 pages, 2015.

[26] L. A. Schipper and G. P. Sparling, "Performance of soil condition indicators across taxonomic groups and land uses," Soil Science Society of America Journal, vol. 64, no. 1, pp. 300-311, 2000.

[27] W. E. Larson and F. J. Pierce, "Conservation and enhancement of soil quality. Pages 175-203 in evaluation for sustainable land management in the developing world," in Proceedings of the International Board for Soil Research and Management (IBSRAM), vol. 2, Bangkok, Thailand, 1991.

[28] M. K. Shukla, R. Lal, and M. Ebinger, "Determining soil quality indicators by factor analysis," Soil and Tillage Research, vol. 87, no. 2, pp. 194-204, 2006.

[29] J. M. Xu, G. L. Zhang, and Z. M. Xie, "Soil quality index and assessment/consultative system," in Soil Quality of China, Z. H. Cao and J. M. Zhou, Eds., pp. 39-89, Science Press, Beijing, China, 2008.

[30] L. T. West, A. J. Tugel, S. A. Wills, C. A. Stiles, and K. Hipple, "Soil survey and inventory of dynamic soil properties in the U.S.A.," in Proceedings of the 19th World Congress of Soil Science; Soil Solutions for a Changing World, R. J. Gilkes and N. Prakongkep, Eds., August 2010, http://www.iuss.org/19th \%20WCSS/Symposium/pdf/2203.pdf.

[31] M. Jahany and S. Rezapour, "Assessment of the quality indices of soils irrigated with treated wastewater in a calcareous semi-arid environment," Ecological Indicators, vol. 109, Article ID 105800, 2020.
[32] Y.-D. Chen, H.-Y. Wang, J.-M. Zhou et al., "Minimum data set for assessing soil quality in Farmland of Northeast China," Pedosphere, vol. 23, no. 5, pp. 564-576, 2013.

[33] V. Memoli, S. C. Panico, L. Santorufo et al., "Do wildfires cause changes in soil quality in the short term?" International Journal of Environmental Research and Public Health, vol. 17, no. 15, 5343 pages, 2020.

[34] K. Nabiollahi, R. Taghizadeh-Mehrjardi, and S. Eskandari, "Assessing and monitoring the soil quality of forested and agricultural areas using soil-quality indices and digital soilmapping in a semi-arid environment," Archives of Agronomy and Soil Science, vol. 64, no. 5, pp. 696-707, 2017a.

[35] X. Li, D. Wang, Y. Ren, Z. Wang, and Y. Zhou, "Soil quality assessment of croplands in the black soil zone of Jilin Province, China: establishing a minimum data set model," Ecological Indicators, vol. 107, Article ID 105251, 2019.

[36] Y. Qi, J. L. Darilek, B. Huang, Y. Zhao, W. Sun, and Z. Gu, "Evaluating soil quality indices in an agricultural region of Jiangsu Province, China," Geoderma, vol. 149, no. 3-4, pp. 325-334, 2009.

[37] S. A. Rezaei, R. J. Gilkes, and S. S. Andrews, "A minimum data set for assessing soil quality in rangelands," Geoderma, vol. 136, no. 1-2, pp. 229-234, 2006.

[38] C. Wu, G. Liu, C. Huang, and Q. Liu, "Soil quality assessment in Yellow River Delta: establishing a minimum data set and fuzzy logic model,” Geoderma, vol. 334, pp. 82-89, 2019.

[39] R. Yao, J. Yang, P. Gao, J. Zhang, and W. Jin, "Determining minimum data set for soil quality assessment of typical saltaffected farmland in the coastal reclamation area," Soil and Tillage Research, vol. 128, pp. 137-148, 2013.

[40] A. S. Abuzaid, A. D. Abdellatif, and M. E. Fadl, "Modeling soil quality in Dakahlia Governorate, Egypt using GIS techniques," The Egyptian Journal of Remote Sensing and Space Sciences, vol. 24, no. 2, pp. 255-264, 2020.

[41] A. A. E. Baroudy, A. M. Ali, E. S. Mohamed et al., "Modeling land suitability for rice crop using remote sensing and soil quality indicators: the case study of the Nile Delta," Sustainability, vol. 12, no. 22, 9653 pages, 2020.

[42] M. K. Abdel-Fattah, E. S. Mohamed, E. M. Wagdi et al., "Quantitative evaluation of soil quality using principal component analysis: the case study of El-Fayoum depression Egypt," Sustainability, vol. 13, no. 4, 1824 pages, 2021.

[43] N. S. Embabi, The Geomorphology of Egypt, Landforms and Evolution, Volume I: The Nile Valley and the Western Desert, 447 pages, Special Publication of the Egyptian Geographical Society, Cairo, Egypt, 2004.

[44] Egyptian Meteorological Authority, Climatic Atlas of Egypt, EMA, Cairo, Egypt, 2011, http://ema.gov.eg/wp/.

[45] Soil Survey Staff, Keys to Soil Taxonomy, USDA-Natural Resources Conservation Service, Washington, DC, USA, 12th edition, 2014.

[46] S. M. Arafat, A. A. Afify, M. A. Nagwan, and M. M. ElSharkawy, "Change detection of land use/land cover categories in the Nile Delta region using remote sensing and GIS," in Proceedings of the SPIE Remote Sensing and SPIE Security + Defence Conference, vol. 9239, Amsterdam, Netherland, 2014.

[47] K. Darwish, S. E. Smith, M. Torab, H. Monsef, and O. Hussein, "Geomorphological changes along the Nile Delta Coastline between 1945 and 2015 detected using satellite remote sensing and GIS," Journal of Coastal Research, vol. 33, no. 4, pp. 786-794, 2017. 
[48] J. Smith, B. Mccarl, P. Kirshen et al., "Egypt's economic vulnerability to climate change," Climate Research, vol. 62, no. 1, pp. 59-70, 2014.

[49] A. Rateb and A. Z. Abotalib, "Inferencing the land subsidence in the Nile Delta using Sentinel-1 satellites and GPS between 2015 and 2019," The Science of the Total Environment, vol. 729, Article ID 138868, 2020.

[50] G. M. Foody, "Harshness in image classification accuracy assessment," International Journal of Remote Sensing, vol. 29, no. 11, pp. 3137-3158, 2008.

[51] FAO, Guidelines for Soil Profile Description, FAO, Rome, Italy, 4th edition, 2006.

[52] D. Sparks, A. Page, P. Helmke et al., Eds., Methods of Soil Analysis, American Society of Agronomy, Madison, WI, USA, 1996.

[53] A. L. Flint and L. E. Flint, "2.2 Particle density," in Methods of Soil Analysis, J. H. Dane and G. Clarke Topp, Eds., American Society of Agronomy, Madison, WI, USA, 2002.

[54] M. Kaufmann, S. Tobias, and R. Schulin, "Comparison of critical limits for crop plant growth based on different indicators for the state of soil compaction," Journal of Plant Nutrition and Soil Science, vol. 173, no. 4, pp. 573-583, 2010.

[55] USGS, Shuttle Radar Topography Mission-New Products in 2005, USGS, Reston, VA, USA, 2005, http://srtm.usgs.gov.

[56] J. Wood, The Geomorphological Characterization of Digital Elevation Models, Ph.D. thesis, University of Leicester, Department of Geography, Leicester, UK, 1996.

[57] O. Planchon and F. Darboux, "A fast, simple and versatile algorithm to fill the depressions of digital elevation models," CATENA, vol. 46, pp. 159-176, 2001.

[58] J. Boehner and T. Selige, "Spatial prediction of soil attributes using terrain analysis and climate regionalisation," in SAGAAnalysis and Modelling Applications, J. Boehner, K. R. McCloy, and J. Strobl, Eds., vol. 115, pp. 13-27, Goettinger Geographische Abhandlungen, Göttingen, Germany, 2006.

[59] I. V. Florinsky, "Computation of the third-order partial derivatives from a digital elevation model," International Journal of Geographical Information Science, vol. 23, no. 2, pp. 213-231, 2009.

[60] E. Dobos, J. Daroussin, and L. Montanarella, An SRTM Based Procedure to Delineate SOTER Terrain Units on the 1:1 and 1: 5 Million Scales, 55 pages, Office for Official Publications of the European Communities, Luxembourg, 2005.

[61] J. W. Rouse, R. H. Haas, J. A. Schell, and D. W. Deering, S. C. Freden, E. P. Mercanti, and M. A. Becker, Monitoring Vegetation Systems in the Great Plains with ERTS. Third Earth Resources Technology Satellite-1 Symposium-Volume I: Technical Presentations. NASA SP-351, 309 pages, NASA, Washington, DC, USA, 1973.

[62] C. J. Tucker, "Red and photographic infrared linear combinations for monitoring vegetation," Remote Sensing of Environment, vol. 8, no. 2, pp. 127-150, 1979.

[63] E. Armenise, M. A. Redmile-Gordon, A. M. Stellacci, A. Ciccarese, and P. Rubino, "Developing a soil quality index to compare soil fitness for agricultural use under different managements in the Mediterranean environment," Soil and Tillage Research, vol. 130, pp. 91-98, 2013.

[64] J. W. Doran and T. B. Parkin, "Defining and assessing soil quality," in Defining Soil Quality for a Sustainable Environment, J. W. Doran, D. G. Coleman, D. F. Bezddick, and B. A. Stewart, Eds., Soil Science Society of America Journal, Madison, WI, USA, pp. 3-21, 1994.
[65] M. Pulido Moncada, D. Gabriels, and W. M. Cornelis, "Datadriven analysis of soil quality indicators using limited data," Geoderma, vol. 235-236, pp. 271-278, 2014.

[66] D. Vasu, S. K. Singh, S. K. Ray et al., "Soil quality index (SQI) as a tool to evaluate crop productivity in semi-arid Deccan plateau, India," Geoderma, vol. 282, pp. 70-79, 2016.

[67] C. Walck, Handbook on Statistical Distributions for Experimentalists, University of Stockholm, Stockholm, Sweden, 2007.

[68] SAS Institute Inc, Multivariate Methods, SAS Institute Inc, Cary, NC, USA, 2018.

[69] M. M. Wander and G. A. Bollero, "Soil quality assessment of tillage impacts in Illinois," Soil Science Society of America Journal, vol. 63, no. 4, pp. 961-971, 1999.

[70] M. Yemefack, V. Jetten, and D. Rossiter, "Developing a minimum data set for characterizing soil dynamics in shifting cultivation systems," Soil and Tillage Research, vol. 86, no. 1, pp. 84-98, 2006.

[71] G. Li, J. Chen, Z. Sun, and M. Tan, "Establishing a minimum dataset for soil quality assessment based on soil properties and land-use changes," Acta Ecologica Sinica, vol. 27, no. 7, pp. 2715-2724, 2007.

[72] M. Pulido, S. Schnabel, J. F. L. Contador, J. Lozano-Parra, and Á. Gómez-Gutiérrez, "Selecting indicators for assessing soil quality and degradation in rangelands of Extremadura (SW Spain)," Ecological Indicators, vol. 74, pp. 49-61, 2017.

[73] P. Li, T. Zhang, X. Wang, and D. Yu, "Development of biological soil quality indicator system for subtropical China," Soil and Tillage Research, vol. 126, pp. 112-118, 2013.

[74] C. A. Seybold, M. J. Mausbach, D. L. Karlen, and H. H. Rogers, "Quantification of soil quality," in Soil Processes and the Carbon Cycle, R. Lal, J. M. Kimble, R. F. Follett, and B. A. Stewart, Eds., CRC Press LLC, Washington, DC, USA, pp. 387-404, 1997.

[75] S. S. Andrews, D. L. Karlen, and C. A. Cambardella, "The soil management assessment framework," Soil Science Society of America Journal, vol. 68, no. 6, pp. 1945-1962, 2004.

[76] M. Diack and D. E. Stott, "Development of a soil quality index for the chalmers silty clay loam from the Midwest USA," in Proceedings of the 10th International Soil Conservation Meeting, D. E. Stott, R. H. Mohtar, and G. C. Steinhardt, Eds., pp. 550-555, Purdue University and the USDA-ARS National Soil Erosion Research Laboratory, West Lafayette, IN, USA, May 1999.

[77] M. A. Liebig, G. Varvel, and J. Doran, "A simple performance-based index for assessing multiple agroecosystem functions," Agronomy Journal, vol. 93, no. 2, pp. 313-318, 2001.

[78] F. Raiesi, "A minimum data set and soil quality index to quantify the effect of land use conversion on soil quality and degradation in native rangelands of upland arid and semiarid regions," Ecological Indicators, vol. 75, pp. 307-320, 2017.

[79] A. Wymore, Model-Based Systems Engineering: An Introduction to the Mathematical Theory of Discrete Systems and to the Tricotyledon Theory of System Design, CRC Press, Boca Raton, FL, USA, 1993.

[80] D. Karlen, N. C. Wollenhaupt, D. C. Erbach et al., "Crop residue effects on soil quality following 10-years of no-till corn," Soil and Tillage Research, vol. 31, no. 2-3, pp. 149-167, 1994.

[81] I. Hussain, K. Olson, M. Wander, and D. Karlen, “Adaptation of soil quality indices and application to three tillage systems in southern Illinois," Soil and Tillage Research, vol. 50, no. 3-4, pp. 237-249, 1999. 
[82] J. D. Glover, J. P. Reganold, and P. K. Andrews, "Systematic method for rating soil quality of conventional, organic, and integrated apple orchards in Washington State," Agriculture, Ecosystems \& Environment, vol. 80, no. 1-2, pp. 29-45, 2000.

[83] D. L. Karlen, M. J. Mausbach, J. W. Doran, R. G. Cline, R. F. Harris, and G. E. Schuman, "Soil quality: a concept, definition, and framework for evaluation (A Guest Editorial)," Soil Science Society of America Journal, vol. 61, no. 1, pp. 4-10, 1997.

[84] J. L. Smith and J. W. Doran, "Measurement and use of $\mathrm{pH}$ and electrical conductivity for soil quality analysis," Methods for Assessing Soil Quality, vol. 49, pp. 169-185, 1997.

[85] P. J. Gregory, L. P. Simmonds, and C. J. Pilbeam, "Soil type, climatic regime, and the response of water use efficiency to crop management," Agronomy Journal, vol. 92, no. 5, pp. 814-820, 2000.

[86] A. Velmurugan, Assessment of soil quality parameters for sustainable production in rice-wheat cropping system, Ph.D. thesis https://krishikosh.egranth.ac.in/handle/1/2031262, Indian Agricultural Research Institute, New Delhi, India, 2000.

[87] R. E. Masto, P. K. Chhonkar, D. Singh, and A. K. Patra, "Soil quality response to long-term nutrient and crop management on a semi-arid inceptisol," Agriculture, Ecosystems \& Environment, vol. 118, no. 1-4, pp. 130-142, 2007.

[88] R. E. Masto, P. K. Chhonkar, D. Singh, and A. K. Patra, "Alternative soil quality indices for evaluating the effect of intensive cropping, fertilization and manuring for 31 years in the semi-arid soils of India," Environmental Monitoring and Assessment, vol. 136, no. 1-3, pp. 419-435, 2008.

[89] K. Gebreyesus, "Impact assessment of climate change on the hydrology of Gojeb river catchment in Western Omogibe River Basin, Ethiopia," M.Sc. thesis, Haramaya University, Haramaya, Ethiopia, 2014.

[90] M. Shanmuganathan and A. Rajendran, "Soil fertility analysis for the cultivation of sugarcane and rice in Thiruvarur area," Current Agriculture Research Journal, vol. 6, no. 3, pp. 407-420, 2018.

[91] E. Velasquez, P. Lavelle, and M. Andrade, "GISQ, a multifunctional indicator of soil quality," Soil Biology and Biochemistry, vol. 39, no. 12, pp. 3066-3080, 2007.

[92] F. Bastida, J. Luis Moreno, T. Teresa Hernández, and C. García, "Microbiological degradation index of soils in a semiarid climate," Soil Biology and Biochemistry, vol. 38, no. 12, pp. 3463-3473, 2006.

[93] C. Zhang, S. Xue, G. B. Liu, and Z. L. Song, "A comparison of soil qualities of different revegetation types in the Loess Plateau, China," Plant and Soil, vol. 347, no. 1-2, pp. 163-178, 2011.

[94] D. H. von Seggern, CRC Standard Curves and Surfaces with Mathematical, Chapman \& Hall/CRC, Boca Raton, FL, USA, 2007, https://doi.org/10.1201/b16001, 2nd edition.

[95] D. L. Karlen and D. E. Stott, "A framework for evaluating physical and chemical indicators of soil quality," in Defining Soil Quality for a Sustainable Environment, J. Doran, D. Coleman, D. Bezdicek, and B. Stewart, Eds., Soil Science Society of America, Madison, WI, USA, 1994.

[96] F. Rahmanipour, R. Marzaioli, H. A. Bahrami, Z. Fereidouni, and S. R. Bandarabadi, "Assessment of soil quality indices in agricultural lands of Qazvin Province, Iran,” Ecological Indicators, vol. 40, pp. 19-26, 2014.

[97] T. Nakajima, R. Lal, and S. Jiang, "Soil quality index of a crosby silt loam in central Ohio," Soil and Tillage Research, vol. 146, pp. 323-328, 2015.
[98] E. G. Gregorich, M. R. Carter, D. A. Angers, C. M. Monreal, and B. H. Ellert, "Towards a minimum data set to assess soil organic matter quality in agricultural soils," Canadian Journal of Soil Science, vol. 74, no. 4, pp. 367-385, 1994.

[99] B. R. Hanson, S. R. Grattan, and A. Fulton, Agricultural Salinity and Drainage: A User's Handbook, University of California, Davis, CA, USA, 2006.

[100] L. Gong, Q. Ran, G. He, and T. Tiyip, "A soil quality assessment under different land use types in Keriya river basin, Southern Xinjiang, China," Soil and Tillage Research, vol. 146, pp. 223-229, 2015.

[101] K. Juhos, S. Szabó, and M. Ladányi, "Explore the influence of soil quality on crop yield using statistically-derived pedological indicators," Ecological Indicators, vol. 63, pp. 366373, 2016.

[102] A. Maity, "Generation of information database of IARI farm using geographical information system," M.Sc. thesis, Indian Agricultural Research Institute, New Delhi, India, 2002.

[103] A. Sánchez-Navarro, J. M. Gil-Vázquez, M. J. DelgadoIniesta, P. Marín-Sanleandro, A. Blanco-Bernardeau, and R. Ortiz-Silla, "Establishing an index and identification of limiting parameters for characterizing soil quality in Mediterranean ecosystems," CATENA, vol. 131, pp. 35-45, 2015.

[104] M. S. Askari and N. M. Holden, "Indices for quantitative evaluation of soil quality under grassland management," Geoderma, vol. 230-231, pp. 131-142, 2014.

[105] M. S. Askari, S. M. O'Rourke, and N. M. Holden, "Evaluation of soil quality for agricultural production using visible-nearinfrared spectroscopy," Geoderma, vol. 243-244, pp. 80-91, 2015.

[106] S. W. Blecker, L. L. Stillings, M. C. Amacher, J. A. Ippolito, and N. M. DeCrappeo, "Development and application of a soil organic matter-based soil quality index in mineralized terrane of the Western US," Environmental Earth Sciences, vol. 68, no. 7, pp. 1887-1901, 2012.

[107] S. Biswas, G. C. Hazra, T. J. Purakayastha et al., "Establishment of critical limits of indicators and indices of soil quality in rice-rice cropping systems under different soil orders," Geoderma, vol. 292, pp. 34-48, 2017.

[108] K. Nabiollahi, R. Taghizadeh-Mehrjardi, R. Kerry, and S. Moradian, "Assessment of soil quality indices for saltaffected agricultural land in Kurdistan Province, Iran," Ecological Indicators, vol. 83, pp. 482-494, $2017 \mathrm{~b}$.

[109] S. Yeilagi, S. Rezapour, and F. Asadzadeh, "Degradation of soil quality by the waste leachate in a Mediterranean semiarid ecosystem," Scientific Reports, vol. 11, no. 1, 11390 pages, 2021.

[110] L. Guo, Z. Sun, Z. Ouyang, D. Han, and F. Li, “A comparison of soil quality evaluation methods for Fluvisol along the lower Yellow River," CATENA, vol. 152, pp. 135-143, 2017.

[111] G. F. Jenks, "The data model concept in statistical mapping," International Yearbook of Cartography, vol. 7, pp. 186-190, 1967.

[112] M. A. North, "A method for implementing a statistically significant number of data classes in the Jenks algorithm," in Proceedings of the Sixth International Conference on Fuzzy Systems and Knowledge Discovery, pp. 35-38, Tianjin, China, 2009.

[113] J. A. Burger and D. L. Kelting, Soil Quality Monitoring for Assessing Sustainable Forest Management, American Society of Agronomy, Madison, WI, USA, pp. 17-52, 2015.

[114] R. Kerry and M. A. Oliver, "Determining nugget: sill ratios of standardized variograms from aerial photographs to krige 
sparse soil data," Precision Agriculture, vol. 9, no. 1-2, pp. 33-56, 2008.

[115] T. P. Robinson and G. Metternicht, "Testing the performance of spatial interpolation techniques for mapping soil properties," Computers and Electronics in Agriculture, vol. 50, no. 2, pp. 97-108, 2006.

[116] ESRI, ArcGIS Desktop: Release 10.8, Environmental Systems Research Institute, Redlands, CA, USA, 2020.

[117] S. Sharma, Applied Multivariate Techniques, 512 pages, John Wiley \& Sons, New York, NY, USA, 1996.

[118] N. D. Misopolinos and J. M. Kalovoulos, "Determination of $\mathrm{CEC}$ and exchangeable $\mathrm{Ca}$ and $\mathrm{Mg}$ in non-saline calcareous soils," Journal of Soil Science, vol. 35, no. 1, pp. 93-98, 1984.

[119] M. E. Sumner and W. P. Miller, "Methods of soil analysis. Part 3. Chemical methods," in Cation Exchange Capacity, and Exchange Coefficients, D. L. Spark, Ed., pp. 65-94, Soil Science Society of America and American Society of Agronomy, Madison, WI, USA, 1996.

[120] M. C. Rowley, S. Grand, T. Adatte, and E. P. Verrecchia, "A cascading influence of calcium carbonate on the biogeochemistry and pedogenic trajectories of subalpine soils, Switzerland," Geoderma, vol. 361, Article ID 114065, 2020.

[121] A. Abuzaid and M. Bassouny, "Multivariate and spatial analysis of soil quality in Kafr El-Sheikh Governorate, Egypt," Journal of Soil Sciences and Agricultural Engineering, vol. 9, no. 8, pp. 333-339, 2018. 